\title{
La ortografía en televisión. Estudio de los informativos de Antena 3, Telecinco y TVE
}

MHCJ no 7 | Año 2016

Artículo no 12 (84)

Páginas 287 a 323

mhjournal.org

\author{
Marián Alonso González|malonsog@us.es \\ Universidad de Sevilla
}

\author{
Palabras clave \\ Televisión; ortografía; erratas; Antena 3; \\ TVE; Telecinco \\ Sumario \\ 1. Introducción. 1.1. Informativos de \\ televisión y grafismo. 2. Objetivos e \\ hipótesis. 3. Metodología. 3.1. Plano \\ Morfosintáctico. 3.1.1. Discordancias. 3.2. \\ Plano Ortográfico. 3.2.1. Tildes. 3.2.2. \\ Puntuación. 3.2.3. Erratas. 3.2.4. Faltas de \\ ortografía. 3.3. Plano Gramatical. 3.3.1. \\ Construcción gramatical. 4. Resultados. 4.1. \\ Antena 3. 4.2. Telecinco. 4.3. Televisión \\ Española. 5. Discusión y conclusiones. 6. \\ Bibliografía.
}

\section{Resumen}

Dada la importancia que tienen los medios de comunicación en la sociedad actual, el

correcto uso del lenguaje debería ser parte de su compromiso cultural con los ciudadanos a los que se dirigen. En este sentido, este artículo pretende analizar y estudiar los errores registrados en los rótulos sobreimpresos que aparecen en los informativos de televisión a fin de determinar su origen, debido a la influencia lingüística que ejercen sobre la población. Para el desarrollo del trabajo empírico se ha escogido la técnica cualitativa del estudio de caso que hemos complementado con un enfoque cuantitativo, de forma que establecemos una perspectiva metodológica mixta que nos permite analizar mejor los errores que entrañan los rótulos de televisión en los programas informativos puros de las cadenas privadas Antena 3 y Telecinco y la pública TVE en su formato de mediodía, por ser los que mayor audiencia poseen. Los resultados apuntan a que la mayoría de los errores responden a la inmediatez imperante en el formato noticioso audiovisual, así como a la limitación de espacio que imponen los rótulos sobreimpresos.

\section{Forma de citar este artículo en las bibliografías}

Marián Alonso González (2016): "La ortografía en televisión. Estudio de los informativos de Antena 3, Telecinco y TVE”, en Miguel Hernández Communication Journal, nº 7, páginas 287 a 323. Universidad Miguel Hernández, UMH (Elche-Alicante). Recuperado el _ de de 20_ de: [ink del artículo en mhjournal.org] 


\title{
Spelling on television. Study of news in the channels Antena 3, Telecinco and TVE
}

\author{
MHCJ no 7 | Año 2016 \\ Artículo no 12 (84) \\ Páginas 287 a 323 \\ mhjournal.org
}

\author{
M arián Alonso González|malonsog@us.es \\ Universidad de Sevilla
}

\section{Keywords}

Television; spelling; mistakes; Antena 3; TVE; Telecinco

\section{Summary}

1. Introduction. 1.1. News of televisión and graphics. 2. Objectives and hypotheses. 3. Methodology. 3.1. Morphosyntactic level. 3.1.1. Mismatches. 3.2. Ortographic level. 3.2.1. Tildes. 3.2.2. Punctuation. 3.2.3. Mistakes. 3.2.4. Spelling mistakes. 3.3. Gramatical level. 3.3.1. Gramatical construction. 4. Results. 4.1. Antena 3. 4.2. Telecinco. 4.3. Televisión Española. 5. Discussion and conclusions. 6. Bibliography.

\begin{abstract}
The mass media have great importance in the current company, for this reason the correct use of the language should be a part of his cultural commitment with the citizens to whom they go. In this order, this paper focuses to analyze and to study the mistakes registered in television's sings to determine his origin and to ask for responsibility, given the linguistic influence that they have on his audience. The author apply a methodology based on indicators qualitative and quantitative to get an useful tool to analyze the mistakes in news in the channels of television Antena 3, Telecinco and TVE in their emission of midday, for being those who posses highest audience. The results show the majority of the mistakes answer to the immediacy of audiovisual format and the constraints of written text in television's sings.
\end{abstract}

\section{How to cite this paper in bibliographies}

Marián Alonso González (2016): “La ortografía en televisión. Estudio de los informativos de Antena 3, Telecinco y TVE”, en Miguel Hernández Communication Journal, nº7, páginas 287 a 323. Universidad Miguel Hernández, UMH (Elche-Alicante). Recuperado el de de 20__ de: [ink del artículo en mhjournal.org] 


\section{Introducción}

En una profesión, la periodística, en la que la palabra se convierte en herramienta, la corrección ortográfica debería ser una exigencia vital para ejercer el Periodismo, sin embargo, son numerosas las ocasiones en las que comprobamos cómo los periódicos aparecen plagados de erratas, pero también de disgrafías y de evidentes faltas de conocimientos ortográficos.

Según la Real Academia de la Lengua Española, la palabra ortografía hace alusión al conjunto de normas que regulan la escritura de una lengua, es decir, el conjunto de signos convencionales que se encarga de "describir y explicar los elementos constitutivos de la escritura de una lengua, así como los principios y criterios que guían tanto la fijación de las reglas como sus usos y sus modificaciones” (RAE, 2011).

La ortografía es el principal instrumento de trabajo del periodista y como tal su conocimiento exhaustivo debería ser su primera obligación, no obstante, como afirma Manuel Seco (2003), no todos los profesionales están a la altura de ese deber, y aunque los que lo incumplen son una minoría, la impresión negativa que producen sobre sus observadores perjudica a la imagen de la mayoría ejemplar.

Esta tendencia es más que evidente en la prensa, donde la desaparición de la figura del corrector y su sustitución por otros medios tecnológicos, así como la inmediatez que imponen los medios digitales, provocan la proliferación de faltas de ortografía en las páginas de los periódicos. En este sentido, afirmaba José Manuel de Pablos, en el I Congreso Internacional de la Lengua Española, que a las empresas no les interesa la pureza del lenguaje sino la cuenta de resultados.

Hacer que los diarios aparezcan limpios de erratas y faltas de ortografía tiene un precio, que es el mantenimiento de equipos de correctores en la nómina fija del periódico. El coste de este sistema de control es superior al coste negativo que en imagen tiene un diario, así que se asume ese peligro cierto, porque es más barato (De Pablos, 1997).

Hoy día, la captura de faltas de ortografías y gazapos se ha viralizado gracias a Internet. De hecho, una búsqueda en Google sobre "faltas de ortografía en medios de comunicación España" da 221.000 resultados. También las redes sociales están contribuyendo a ello, tal es el caso de la página de Facebook (2016) "Faltas de ortografía en medios de comunicación" (https://www.facebook.com/Faltas-de-ortografía-en-medios-de-comunicación), dedicada a registrar las erratas halladas en los medios impresos. Este fenómeno también puede apreciarse en televisión donde los errores se convierten en la materia prima que nutre muchos programas de zapeo.

Los medios sociales convierten a los ciudadanos en lo que Cremades (2007) denomina nodos de red, pues a través de su interacción configuran conexiones consideradas de alto clustering, ya que 
son redes densamente conectadas a nivel local, lo cual influye de forma proporcional en el proceso de transmisión de la información. Debido a su "estructura de comunidad y a su carácter asortativo" (Buldú, 2011), es decir, a la capacidad de los distintos nodos para agruparse con otros parecidos a ellos, la difusión adquiere un estatus viral, hasta el punto de que sea irrelevante quién inicia un proceso de difusión, ya que la ausencia de propagadores influyentes es precisamente lo que le otorga una mayor fuerza de difusión.

Los medios de comunicación tienen un profundo compromiso cultural con la sociedad a la que van dirigidos. En este sentido, dice Castillo (2005:13) que "están obligados, en cierta medida, a mantener el equilibrio para que no se olvide la importancia de la unidad de la lengua dentro de la comunidad hispanohablante".

Una de las características de la televisión es la inmediatez informativa, sin embargo, esa rapidez choca con la necesidad de disponer de un tiempo determinado para completar una noticia televisiva y así ofrecer unos conocimientos fundados a la audiencia.

Según recoge el ordenamiento jurídico español en su artículo 128 de la Constitución Española, la televisión es un servicio público esencial cuya finalidad ha de ser "la de satisfacer el interés de los ciudadanos y la de contribuir al pluralismo informativo, a la formación de una opinión pública libre y a la extensión de la cultura" y en este sentido, manifiesta Bobo (2005) que sus tres funciones básicas son: informar, divertir y formar.

La propia Real Academia Española, al redactar la $22^{\mathrm{a}}$ edición de su diccionario (2011), utiliza los textos de la prensa como referencia y les da la misma importancia que a los textos surgidos de las plumas de los grandes escritores, pues "los verdaderos maestros del español son los medios de comunicación, que se encargan de difundir los nuevos usos de la lengua" (Gómez, 2005:55).

Esta función social de la televisión se incumple cuando la ortografía y la sintaxis pasan a un segundo plano y no existe exigencia respecto al uso del lenguaje. En este sentido, a lo largo del presente artículo hemos estudiado los errores registrados en la pequeña pantalla a fin de categorizarlos y poner de manifiesto una falta de rigurosidad profesional en el ámbito del periodismo audiovisual. Para ello, hemos desarrollado un método de investigación de análisis de contenido que hemos complementado con técnicas cuantitativas a fin de evidenciar el gran número de errores que entrañan los rótulos de televisión de carácter informativo.

\subsection{Informativos de televisión y grafismo}

El telediario o informativo es un programa en el que se cuentan noticias de interés público que responden a las informaciones de los acontecimientos más sobresalientes del día. Con periodicidad diaria, se emite en varias ediciones y aborda la actualidad preferentemente a través del género informativo puro que es la noticia, aunque también se nutre de otros híbridos como el reportaje y la entrevista. 
En la televisión generalista las formas externas de la información han ido cambiando de manera perceptible. En la actualidad, los espacios informativos tienen mayor duración para poder insertar publicidad y cumplir las normativas vigentes, al tiempo que "incorporan novedades expresivas, inserción de rótulos, infografías y animaciones, espacios para reportajes junto a la exhibición de medios técnicos" (Pestano, 2008:455).

Los informativos tienen una consideración especial dentro la empresa informativa ya que se identifican con la parte de la imagen que la empresa quiere dar de sí misma, al tiempo que están perfectamente instalados en la temporalidad diaria, ya que la audiencia los considera una fuente de información fiable debido a que "sus imágenes poseen un alto grado de verosimilitud mientras que los sonidos se encargan de efectuar un cierre semántico que da sentido a las primeras" (Crigler et Al., 1994:138). Asimismo, poseen una consideración especial en términos económicos, pues suponen una banda de paso entre programaciones.

Según datos registrados por Kantarmedia (2015), entre los cuarenta programas más vistos en el pasado mes de julio ocho fueron informativos. Ordenados por máxima audiencia, el primer telediario aparece en el puesto catorce, se trata del informativo de las 21 horas de Telecinco, seguido en los puestos 23 y 24 por los del mediodía de Telecinco y Antena 3, respectivamente. A partir del puesto 30 encontramos el Telediario 1 de TVE (33), Antena 3 Noticias Fin de Semana (34), Telediario 2 (36) y Telediario fin de semana (39), ambos de TVE.

Afirma Pestano (2008) que la estructura del informativo de televisión responde a un supuesto conocimiento de la audiencia por parte de los responsables de la emisión, de manera que "el director de informativos y el editor de cada programa ajustan la sucesión, contenido y duración de las piezas a partir de criterios de noticiabilidad y selección explícitos e implícitos" (Guerrero Serón, 1999:110).

Autores como Pérez (2003:83) también destacan que:

El esquema del interés teórico por la emisión debe ser lo más parecido a unos dientes de sierra, donde los picos corresponden a las noticias de inicio de cada bloque. Los mismos dientes de sierra deberían apreciarse también dentro de cada bloque.

Por lo general, la estructura codificada que respeta la mayor parte de los informativos es la compuesta por inicio, titulares, desarrollo o corpus y cierre. Esas cuatro partes de la estructura del informativo se encuentran encadenadas en la escaleta, la cual muestra la composición del informativo con su orden jerárquico. El orden es, junto con la duración de la noticia, un componente importante que nos informa "de la relevancia de un suceso o, mejor dicho, de la 
importancia que un determinado medio de comunicación, por medio de un informativo, otorga a ese suceso" (Pastor, 2014:808).

Este modelo es inherente al mensaje periodístico, tanto en los medios audiovisuales como en la prensa:

El modelo es la representación cognitiva crucial que los comunicadores (tanto periodistas como lectores) utilizan para comprender los acontecimientos y las situaciones informativas. Este es también el modelo que el periodista desea transmitir a los lectores a través de las informaciones periodísticas. Y las estructuras de esta información periodística están organizadas de manera tal que el modelo propuesto pueda efectivamente comunicarse: lo que ocupa un lugar alto en la jerarquía del modelo también aparecerá en un nivel alto en la jerarquía estructural del texto periodístico, en los titulares o en el encabezamiento (Dijk, 1990:256-257).

Para favorecer la compresión general de las noticias los informativos se apoyan en el grafismo, un componente expresivo que tiene cada vez mayor protagonismo en las informaciones televisivas debido a la importancia que le otorgan sus propiedades didácticas, visuales, estéticas y versátiles.

La introducción de los gráficos ha supuesto una revolución en la presentación de los informativos, ya que dota al canal de una personalidad diferenciada, y en esto el noticiero es un vehículo fundamental para su imagen. Según Valero (2009:180) sus principales cualidades pueden sintetizarse en:

1. Clarifican asuntos complicados.

2. Cubren deficiencias cuando no hay imágenes de un acontecimiento.

3. Son específicos y generados por la información de la que se nutren, aunque sea indirectamente.

4. Enfatizan, subrayan o ilustran contenidos esenciales sintéticamente.

5. Entrelazan ideas o comparan sucesos lejanos espaciotemporalmente explicando el verdadero sentido.

Atendiendo a la complejidad de sus lenguajes se puede establecer una triple clasificación de los grafismos televisivos: los infogramas o unidades gráficas complejas en los que concurren los lenguajes icónicos y verbales pero que no tienen suficientes elementos como para hacer un discurso completo de la historia; las unidades complejas asociadas al hilo discursivo de la narración, y las unidades gráficas elementales, aquellas de fácil identificación y reconocimiento que son denominadas por Valero (2009:184) como "grafismo ortotipográfico".

Dentro de estas unidades simples se encuadran los rótulos, expresiones emitidas oralmente por personajes relevantes de actualidad, especialmente en discursos largos, para visualizar y ordenar las principales ideas, con un cierto sentido de resalte para los intérpretes (Pericot, 2002:26). Aunque también se pueden presentar como puntos de lectura del discurso principal, a modo de elementos que complementan y aclaran las "lagunas informativas de las presentaciones icónicas en su imprecisión figurativa o contextualizadora" (Valero, 2009: 185). 
La unidad mínima del análisis de contenido de este trabajo de investigación son los rótulos que aparecen insertados en las piezas informativas que conforman el noticiero, con independencia de que se traten de sumarios, titulares o noticias. Según Hervás (2002), los rótulos constan de tres partes: el título, que es una palabra o frase que presenta el programa en cuestión; el subtítulo, la palabra o frase que concede sentido a una imagen; y el cartón, es decir, el inter-título o pantalla completa que da sentido a una secuencia.

Hasta la década de los ochenta no llegan los equipos informáticos a los departamentos de grafismo de las televisiones y hasta entonces se trabajaba con métodos bastante rudimentarios. De hecho, al comienzo de la televisión los rótulos televisivos tenían que confeccionarse cada día y era muy común el uso del pasarótulos, una mesa elevada hasta la altura de la cámara en la que se disponían una serie de cartones, que contenían información, unos detrás de otros, una persona lanzaba hacia delante cada cartón y aparecía el de detrás, esto se emitía en directo.

Toda la información y los elementos gráficos eran recortados y pegados en estos cartones, o bien pintados a mano. Durante este periodo, además de diseñadores, se precisaban ilustradores que tuvieran destreza y fueran capaces de resolver rápidamente una imagen. La tipografía se dibujaba a mano, el trabajo era meticuloso y sin vuelta atrás si se cometía algún fallo.

La llegada del Letraset, una técnica de rotulación y diseño basada en la reproducción de las letras mediante caracteres adhesivos, supone una revolución, porque ya no hay que dibujar la tipografía que era un trabajo muy laborioso.

La mayor parte de los rótulos televisivos que se requerían a diario se hicieron durante muchos años con tipos metálicos de composición manual que producían letras blancas sólidas sobre cartones de color negro (de ahí el uso actual de la palabra cartón como sinónimo de intertítulo). Los títulos, subtítulos y rótulos se colocaban carácter por carácter utilizando el mismo principio desarrollado para la imprenta por Johannes Butenberg quinientos años antes (Hervás, 2002: 40).

En la actualidad los rótulos son digitales y se almacenan para su recuperación y transmisión al momento. Estos letreros que ayudan al espectador a situarse y no perder el hilo argumental son incluidos en los programas informativos por grafistas y rotulistas cuando se produce la postproducción de los vídeos y es por ello que, sin las prisas que exige la inmediatez del directo, no se entiende la existencia de erratas y faltas de ortografías.

Pese a la falta de estudios científicos que existen sobre los mismos en los últimos años hemos asistido a un auge de la rotulación como consecuencia directa del "desarrollo de las nuevas tecnologías de la información y la comunicación" (Andueza y Pérez, 2014:612), pero también debido al poder persuasor que tiene la palabra escrita frente a la hablada. 
La asociación entre mensaje persuasivo, mensaje visual y difusión masiva, afecta y modela los esquemas figurativos de nuestra mente, así como a las estructuras que utilizamos para construir nuestras imágenes del mundo. (...) Y además, utiliza estos elementos semántico-visuales para ejercer presión persuasiva, generalmente eficaz, cuando no claramente alienadora. El lenguaje de la televisión controla estrechamente la realidad por medio de símbolos visuales de comprensión general, y desde ellos controla parcelas de conciencia y del comportamiento (Roiz, 1994:81).

Existe pues un doble poder persuasor, el tecnológico y el de los mensajes codificados visualmente, es decir, los rótulos, que contribuyen a lograr más eficacia. Por tanto, hay que entender estos recursos como un componente más en la expresión televisiva, que disfrutan de autonomía y se integran como un elemento más dentro del universo audiovisual (Cebrián, 2003).

Para no absorber la atención, los rótulos cuenta con ciertas características que Cebrián (2003:205) establece como:

Tipografía: fuente, tamaño, grosor/profundidad, claridad, dimensión, color, rasgos expresivos.

Topografía: lugar que ocupan en la pantalla.

Modo de presentación: letras fijas o en movimiento.

En base a la mezcla de estas características encontramos tres tipos de rótulos en los programas informativos:

Totales: Identifican a las personas que aparecen hablando en pantalla y sirven para conocer el nombre y cargo de aquellos que ofrecen los totales, presentadores del informativo en directo, reporteros o redactores de cada una de las piezas, así como el cámara y el montador.

Localizadores: Indican la fecha y lugar de lo que estamos viendo. Incluye la frase "conexión en directo".

Descriptivos: Son aquellos que sirven para resaltar el aspecto más relevante de la noticia en una o dos frases máximo.

Entre sus rasgos lingüísticos peculiares que poseen los rótulos, destacan Andueza y Pérez (2014:615) el empleo del estilo nominal impersonal, su preferencia por el tiempo presente en los verbos, la abundancia de nombres propios gramaticales y artículos definidos, la utilización de varias clases de elipsis para economizar palabras y su receptividad para el contagio de otros campos léxicos más populares.

En cuanto a la tipografía, los rótulos suelen usar las letras de palo seco, es decir, aquellas que permiten un mejor y mayor reconocimiento de la letra, facilitando su lectura, para tal fin también se utilizan escalas horizontales y espacios interletraje amplios. Los textos suelen ser cortos, dos 
líneas máximos, pues su lectura tiene un tiempo limitado, y por lo general presentan letras grandes, en negativo sobre fondos oscuros y en caja alta o baja, según la cadena.

En el caso de TVE se utiliza una especie de título, sintetizado en un máximo de tres palabras, recuadrado en azul y con letras impresas en blanco, inmediatamente debajo, en negro sobre blanco, en versales y bandera izquierda se desarrolla el texto. El formato utilizado por Antena 3 es similar, salvo que cambia la trama azul por una roja y su texto aparece en altas y bajas. Telecinco varía un poco el diseño, el título admite hasta cinco palabras que van en negro sobre fondo tramado azul claro y justificado en el centro-derecha de la pantalla, a continuación, el texto aparece en blanco sobre fondo azul, en altas y bajas, y hasta un máximo de dos líneas.

Las características redaccionales de los rótulos vienen definidas por los propios libros de estilo de las cadenas. Así pues, para TVE conviene ponderar la importancia del rótulo que acompaña al titular porque condensa la noticia en muy pocas palabras, llegando, incluso, esas pocas noticias a resultar "más elocuentes que todo el texto de la noticia". A la hora de su redacción el ente recomienda "no distraer al espectador con rótulos extensos y/o poco enriquecedores de la información principal", así como extremar la precaución en la escritura del texto, pues "la reducción de filtros correctores pueden propiciar errores, especialmente ortográficos" (RTVE, 2015).

Antena 3 y Telecinco carecen de Libro de Estilo, tan sólo encontramos un código deontológico de Atresmedia Corporación (2012) en el que se recoge, entre otros aspectos, su compromiso con la responsabilidad en los contenidos, los cuales no pueden herir la sensibilidad de la audiencia, así como cumplir de una manera clara y definida con los principios de separación de actividades con el objetivo de evitar posibles conflictos de intereses.

En el ámbito de los informativos, Atresmedia especifica que se separarán con claridad y de modo explícito la información de la publicidad, los contenidos puramente periodísticos de los comerciales, al tiempo que se diferenciará de forma inequívoca los contenidos informativos de aquellos que suponen una interpretación o comentario crítico en cualquier ámbito de la actualidad.

\section{Objetivos e hipótesis}

La hipótesis de partida de este estudio es que existe una actitud laxa respecto al cuidado de la ortografía en los rótulos de televisión, un aspecto que tiene que ver con la no supervisión del lenguaje escrito empleado en los programas y que atenta contra la responsabilidad que tiene el periodista de escribir bien las historias y hacerlas inteligibles, especialmente en los telediarios, programas informativos por excelencia e imagen de la cadena. 
Partiendo de esta hipótesis, el principal objetivo de esta investigación es poner de manifiesto la falta de rigurosidad y el gran número de errores que entrañan los rótulos de televisión en los programas informativos puros. Basándonos en los datos de audiencia hemos elegido para nuestro estudio la edición mediodía de los informativos de las cadenas privadas Antena 3 y Telecinco y la pública TVE.

Junto al objetivo principal nos marcamos otros secundarios que son:

- Determinar la tipología de las erratas detectadas, precisando si son disgrafías o errores ortográficos comunes.

- Establecer una comparativa entre las distintas cadenas de nuestro estudio a fin de determinar cuál es la que menor atención presta a las normas ortográficas.

- Establecer una comparativa entre las erratas detectadas en los bloques de información general y deportes.

- Determinar si las erratas se producen en mayor medida en fin de semana o en días laborables.

\section{Metodología}

Para el desarrollo del trabajo empírico hemos escogido la técnica cualitativa del estudio de caso, un método de investigación de gran relevancia para el desarrollo de las ciencias humanas y sociales pues implica un proceso de indagación caracterizado por el examen sistemático y en profundidad de casos particulares (Barrio et Al., 2010).

El método cualitativo es bastante popular y eficaz a la hora de analizar los contenidos mediáticos a través de aplicaciones concretas, pues el carácter objetivo y sistemático de los datos recogidos a través de esta técnica que permite "formular a partir de ciertos datos, inferencias reducibles y válidas que puedan aplicarse a su contexto” (Krippendorff, 1990:23).

La particularidad más característica de ese método es el estudio intensivo y profundo de un/os caso/s, entendiendo éste como un "sistema acotado" por los límites que precisa el objeto de estudio, pero enmarcado en el contexto global donde se produce (Muñoz y Muñoz, 2001), lo cual permitiría, según Thomas (2011) probar procedimientos, identificar problemas y seleccionar variables e instrumentos de medición pertinentes al estudio.

Con objeto de obtener una acumulación ordenada y estructurada de datos que nos facilite la extracción de inferencias de interés para los objetivos de esta investigación, hemos completado nuestro estudio con un enfoque cuantitativo, de forma que hemos establecido una perspectiva 
metodológica mixta cuyas ventajas han sido destacadas por distintos autores (Creswell y Plano, 2011) en respuesta a la oposición dicotómica entre ambos planteamientos.

La metodología mixta nos permite una comprensión del problema de investigación en el cual se articula la utilización de estadísticas y la medición de determinados fenómenos, propios de lo cuantitativo, con la exploración en profundidad de la problemática examinada y la extracción y comprensión de los significados vinculados las mismas, característico de lo cualitativo.

Para alcanzar los objetivos específicos de esta investigación, y confirmar o refutar la hipótesis de partida, hemos realizado el seguimiento de los informativos de mediodía de las cadenas de emisión nacional TVE, pública, y las privadas Telecinco y Antena 3, por ser, según los últimos datos del EGM (2015) las que un mayor número de espectadores aglutinan, sumando entre todas ellas el 38,7\% de la cuota de espectadores en su franja de emisión.

La ponderación de las mediciones sitúa a Antena 3 como el informativo líder de la franja sobremesa de lunes a domingo, liderazgo que repite en simulcast, es decir, la suma de la audiencia total de un programa que se emite de forma simultánea en dos canales distintos.

Para alcanzar los objetivos específicos de esta investigación, y confirmar o refutar la hipótesis de partida, hemos analizado un total de 1.605 rótulos aparecidos en las 45 piezas informativas que fueron emitidas por estas tres cadenas durante la primera quincena del mes de julio. Las fechas responden a la necesidad de que los datos obtenidos fueran de total actualidad y el plazo de análisis fue establecido en quince días por considerar que se trata de un periodo suficiente para poder desarrollar un correcto estudio longitudinal.

De igual forma, hemos estudiado tanto el noticiero como el espacio dedicado a la información deportiva a fin de equiparar las emisiones privadas con las de la televisión pública, que concibe el producto informativo como un todo y no hace distinciones de bloques.

$\mathrm{Al}$ no existir estudios previos sobre este tema en el ámbito audiovisual hemos recurrido a los planos lingüísticos referenciados por Barros (2007: 152-153) en su estudio de la prensa: los planos morfosintácticos, ortográficos y gramaticales. Dentro de ellos hemos categorizado los errores detectados en torno a seis variables que quedan articuladas de la siguiente manera:

Plano morfosintáctico: Discordancias.

Plano ortográfico: Tildes, Puntuación, Faltas de ortografía y erratas.

Plano gramatical: Construcciones.

\subsection{Plano Morfosintáctico}

\subsubsection{Discordancias}


Las discordancias son errores en la expresión que se caracterizan por no cumplir una o varias de las reglas de concordancia obligatorias en español. Según el Diccionario Panhispánico de Dudas de la RAE, la concordancia es la coincidencia obligada de determinados accidentes gramaticales (género, número y persona) entre distintos elementos variables de la oración.

En términos generales se pueden distinguir dos tipos de concordancia, la nominal, que hace referencia a la coincidencia de género y número, y la verbal, entre número y persona. A pesar de existir casos especiales, las reglas generales de la concordancia gramatical establecen:

La coordinación de dos o más sustantivos o pronombres en singular, siempre que cada uno de ellos se refiera a un ente distinto, forma un grupo que concuerda en plural con el adjetivo o el pronombre, o con el verbo del que son sujeto.

La coordinación de dos o más sustantivos o pronombres de diferente género gramatical forma un grupo que concuerda en masculino con el adjetivo o con el pronombre.

Si entre dos o más elementos coordinados figura un pronombre de segunda persona (y ninguno de primera), la concordancia con el verbo y con los demás pronombres se establece en segunda persona del plural.

\title{
3.2. Plano Ortográfico
}

\subsubsection{Tildes}

Conocidas también como acento gráfico u ortográfico, se trata de una:

\begin{abstract}
"rayita oblicua que, colocada sobre una vocal, indica que la sílaba de la que forma parte es tónica. La tilde debe trazarse siempre de derecha a izquierda, esto es, como acento agudo ('), y no de izquierda a derecha ('), trazo que corresponde al acento grave, que carece de uso en español: camión, no camiòn. El uso de la tilde se atiene a una serie de reglas que se detallan a continuación y que afectan a todas las palabras españolas, incluidos los nombres propios. Sobre la acentuación de palabras de origen extranjero" (RAE: 2010).
\end{abstract}

En español, aquella sílaba que en su pronunciación se lleva el golpe de voz se denomina tónica, y en base a ello existen cuatro tipos de palabras:

Agudas: la sílaba tónica es la última.

Llanas o graves: la sílaba tónica es la penúltima.

Esdrújulas: la sílaba tónica es la antepenúltima.

Sobresdrújulas: la sílaba tónica es anterior a la antepenúltima. 
Por lo general, la acentuación gráfica de las palabras polisílabas atiende a las siguientes reglas:

Las palabras agudas llevan tilde cuando terminan en -n, en -s o en vocal: balón, compás, café, colibrí, bonsái; pero si terminan en -s precedida de otra consonante, se escriben sin tilde: zigzags, robots, tictacs. Tampoco llevan tilde las palabras agudas que terminan en -y, pues esta letra se considera consonante a efectos de acentuación: guirigay, virrey, convoy, estoy.

Las palabras llanas llevan tilde cuando no terminan en -n, en -s o en vocal: clímax, hábil, tándem. También se acentúan cuando terminan en -s precedida de otra consonante: bíceps, cómics, fórceps; y cuando terminan en -y, pues esta letra se considera consonante a efectos de acentuación: póney, yóquey.

Las palabras esdrújulas y sobresdrújulas siempre llevan tilde: cántaro, mecánica, cómetelo.

A las reglas generales de acentuación se añaden algunas excepciones como:

Las palabras de una sola sílaba no se acentúan nunca gráficamente, salvo en los casos de tilde diacrítica, que es aquel acento gráfico que permite distinguir palabras con idéntica forma pero que pertenecen a categorías gramaticales diferentes (de preposición y dé del verbo dar).

Los adverbios que acaban en -mente llevarán tilde si en la forma primitiva lo llevaban.

Los diptongos y triptongos siguen las normas generales de acentuación y se pondrán tildes en la vocal que suena más fuerte.

De igual forma, las mayúsculas deben escribirse con tilde si les corresponde llevarla según las reglas de acentuación gráfica del español, tanto si se trata de palabras escritas en su totalidad con mayúsculas como si se trata únicamente de la mayúscula inicial.

\subsubsection{Puntuación}

Los signos de puntuación son aquellos elementos que nos permiten marcar las pausas y la entonación con la que deben leerse los enunciados, organizar el discurso y sus diferentes elementos para facilitar su comprensión, evitar posibles ambigüedades en textos que sin su empleo podrían tener interpretaciones diferentes y señalar el carácter especial de determinados fragmentos de texto-citas, incisos, intervenciones de distintos interlocutores en un diálogo, etc.

Los signos de puntuación son: comas, comillas, corchetes, dos puntos, interrogación y exclamación, paréntesis, punto, puntos suspensivos, punto y coma y raya. 


\subsubsection{Erratas}

Equivocaciones materiales cometidas en lo impreso y que pueden ser atribuidas a la velocidad con la que se escribe y a una ausencia de cuidado.

\subsubsection{Faltas de ortografía}

Entendidas como la equivocación material cometida en lo impreso derivadas del desconocimiento de la regla ortográfica. Utilizaremos como referencia las faltas ortográficas en la escritura de palabras en los que aparecen fonemas representados por más de un grafema. Son los errores de: ch, II, qu, rr, c, x, y, ce, ci (que, qui), ge, gi (gue, gui), gue, gui (güe, güi), np, nb (mp, $\mathrm{mb}$ ), desunión de consonantes líquidas, mayúscula por minúscula o viceversa.

\subsection{Plano Gramatical}

\subsubsection{Construcción gramatical}

La construcción gramatical se refiere a la articulación de oraciones de acuerdo con las reglas precisas de la gramática e incluye temas coincidentes, verbos, adjetivos y sustantivos, así como la utilización correcta de los adverbios. También contempla la comprensión de la estructura paralela y evitar errores comunes como el mal uso de la cláusula del pretérito imperfecto del modo subjuntivo.

En el lenguaje televisivo la construcción gramatical responde al orden lógico de Sujeto+Verbo+Predicado, lo que a nivel informativo considera Romero (2005:134) "el temarema, y la alteración de ese orden conlleva fenómenos de rematización".

La elaboración de noticias para la televisión, afirma Morales que se efectúa controlando principalmente dos niveles de estructuración de la información, "la Macro estructura o Coherencia semántica global y la Micro estructura o Coherencia sintáctica" (2001:2). La primera hace referencia, según Huertas y Perona (1999), a cómo los elementos que componen un texto permiten deducir al lector o escucha que las diferentes partes forman un todo, mientras que la coherencia sintáctica implica la concordancia entre las palabras y la relación entre las frases que componen cada una de las unidades subordinadas del mensaje.

El control de ambos niveles de estructuración del mensaje es indispensable para facilitar una correcta lectura e interpretación de la información.

\section{Resultados}

Durante el periodo de nuestro estudio hemos analizado un total de 1.605 rótulos correspondientes a 45 boletines informativos. De ellos, 699 pertenecen a TVE, 411 a Telecinco y 525 a Antena 3 (Ver Tabla 1). 
Tabla 1. Rótulos y erratas registrados por las cadenas entre el 1 y el 15 de julio de 2015

\begin{tabular}{|l|l|l|}
\hline Cadena & Rótulos & Erratas \\
\hline TVE & 699 & 76 \\
\hline Telecinco & 411 & 69 \\
\hline Antena 3 & 525 & 20 \\
\hline
\end{tabular}

Fuente: Elaboración propia

En el caso de TVE hemos registrado 76 erratas, lo que supone el 10,87\% de los rótulos totales emitidos. Por su parte, Antena 3 anota 20 erratas, un 3,87\%, mientras que Telecinco es la cadena que más incorrecciones presenta, con un 16,78\% (Ver Gráfico 1).

Gráfico 1. Porcentaje de rótulos inexactos detectados por cadenas

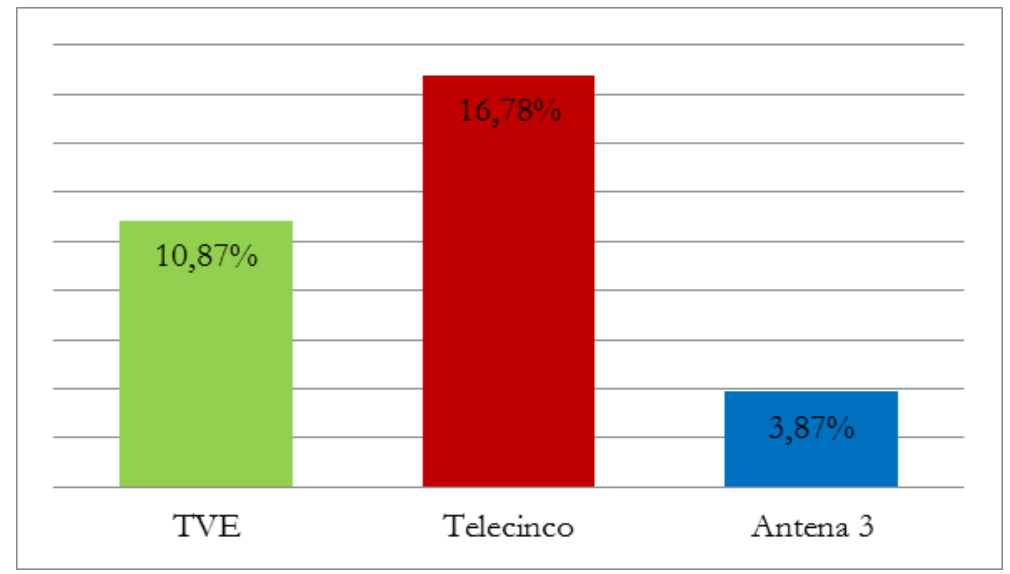

Fuente: Elaboración propia

Por tipología, los errores más abundantes son ortográficos, seguidos de los gramaticales y los morfosintácticos, siendo Telecinco y Televisión Española las cadenas que incurren en un mayor número de fallos (Ver Gráfico 2). 
Gráfico 2. Tipología de errores por cadenas

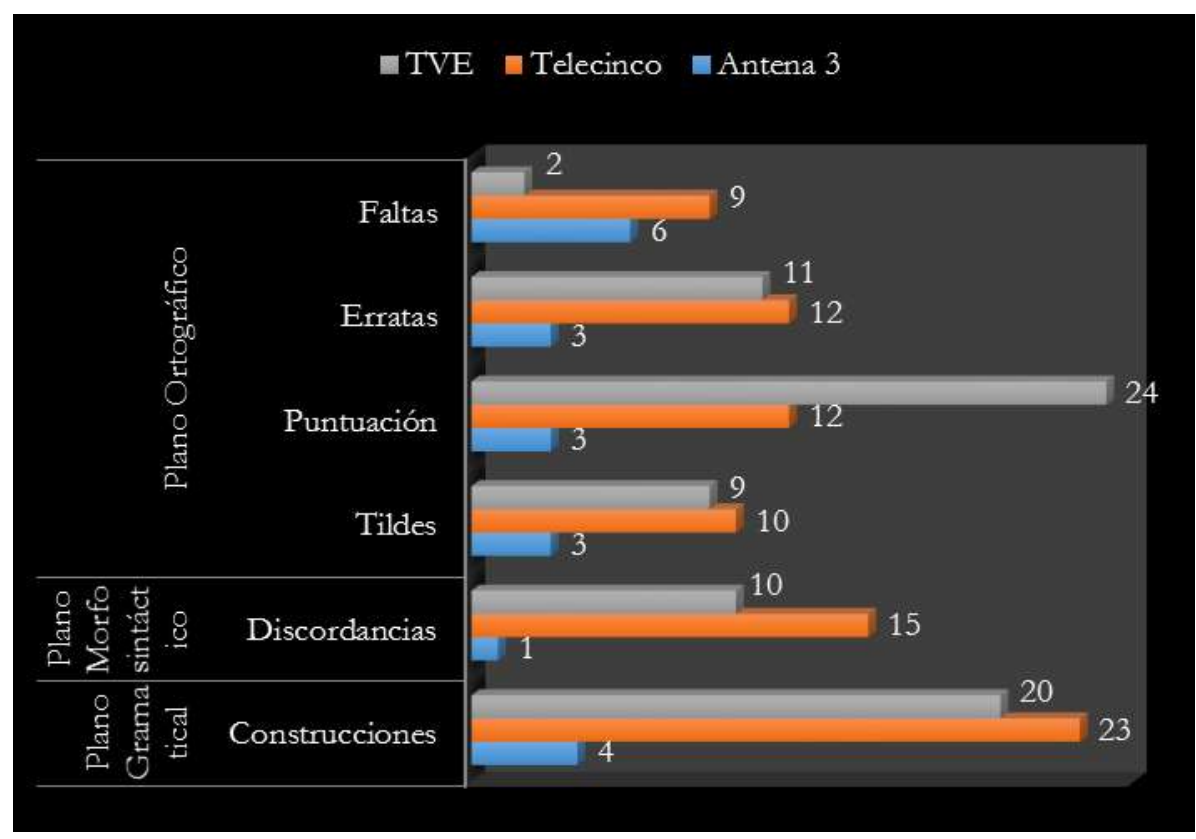

Fuente: Elaboración propia

En el bloque deportivo hemos analizado 253 rótulos, habiendo detectado un menor número de errores en las cadenas privadas que en la pública (Ver Tabla 2). Así, mientras Telecinco y Antena 3 yerran ambas en el 5\% de sus textos, Televisión Española lo hace en el 17,1\% de sus rótulos, porcentaje bastante superior al anotado en el bloque de información general (10,8\%).

Tabla 2. Rótulos y erratas registrados en el bloque de Deportes

\begin{tabular}{|l|l|l|}
\hline Cadena & Rótulos & Erratas \\
\hline TVE & 76 & 13 \\
\hline Telecinco & 60 & 3 \\
\hline Antena 3 & 117 & 6 \\
\hline
\end{tabular}

Fuente: Elaboración propia

Los errores más abundantes vuelven a ser de tipo ortográfico, fundamentalmente ausencias de tildes y faltas de puntuación. Le siguen los relativos al Plano Gramatical, observándose una menor calidad en la composición de las frases, un aspecto en el que destaca sobre todo Televisión Española (Ver Gráfico 3). 
Gráfico 3. Tipología de errores en el bloque de Deportes por cadenas

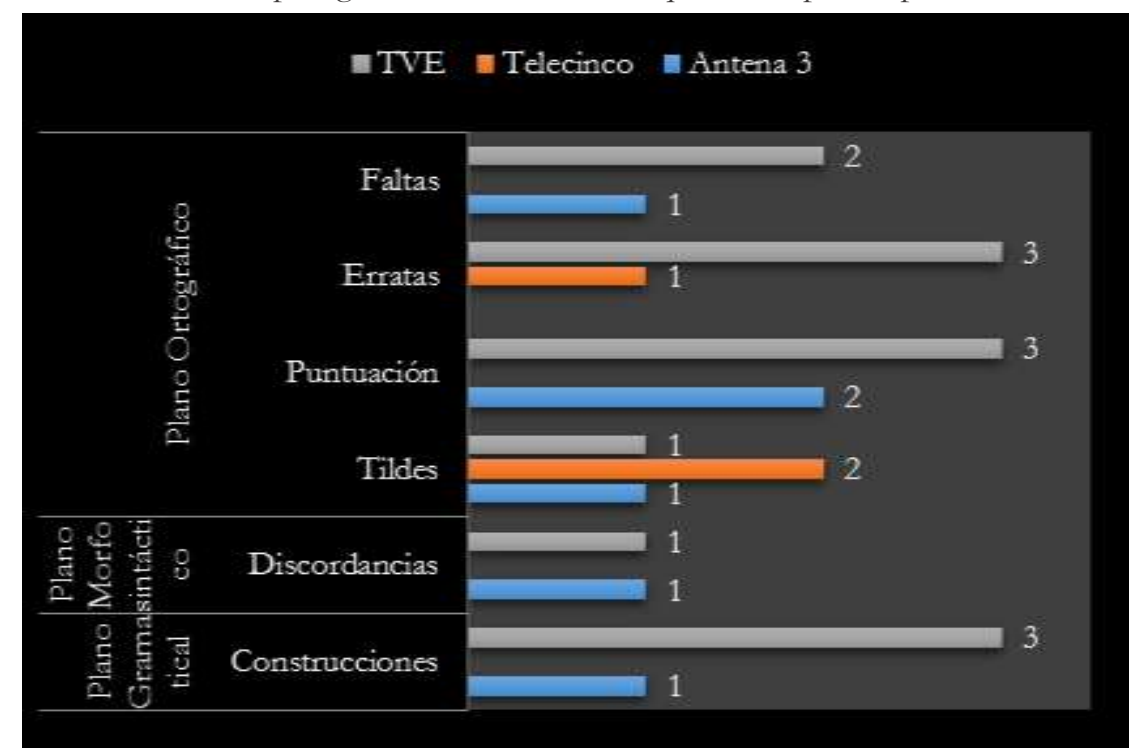

Fuente: Elaboración propia

La frecuencia de errores aumenta significativamente durante los fines de semana, llegando al $25 \%$ en el caso de Antena 3 y TVE, y al 28,9\% en Telecinco (Ver Tabla 3). Por el contrario, durante el fin de semana no se registran erratas en el bloque de deportes.

Tabla 3. Rótulos con erratas registrados en días laborables y fin de semana.

\begin{tabular}{|l|l|l|}
\hline Cadena & Laborables & Fines de Semana \\
\hline TVE & 57 & 19 \\
\hline Telecinco & 49 & 20 \\
\hline Antena 3 & 15 & 5 \\
\hline
\end{tabular}

Fuente: Elaboración propia

Los errores de índole ortográfico continúan siendo los más abundantes, especialmente, los correspondientes a las faltas (32\%). A nivel morfosintáctico y gramatical destaca Telecinco. La cadena de Mediaset es la que peor articula sus oraciones observándose en fin de semana una mayor incidencia en la ausencia de correspondencia nominal, es decir, entre género y número (Ver Gráfico 4). 
Gráfico 4. Tipología de errores en el bloque de Deportes por cadenas

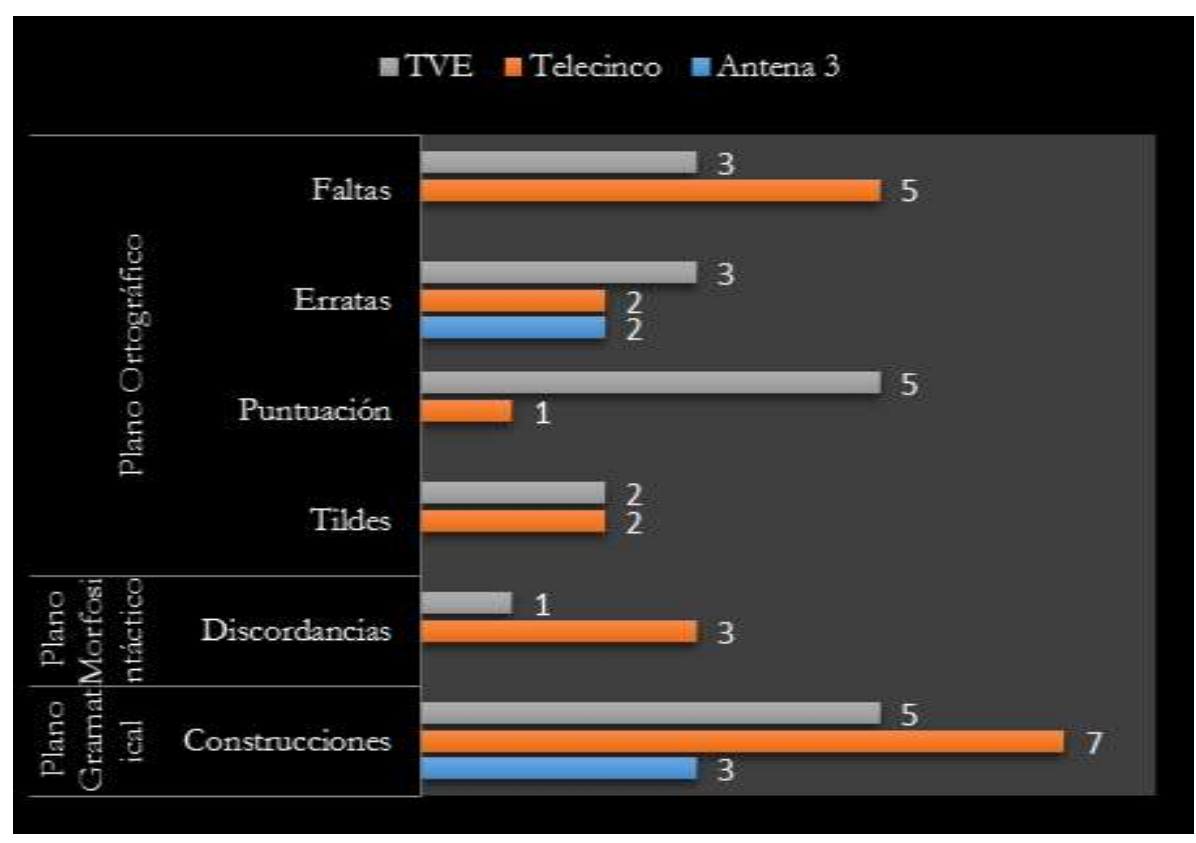

Fuente: Elaboración propia

\subsection{Antena 3}

En el caso de Antena 3 hemos registrado un total de 20 rótulos que contienen errores. La mayoría son de tipo ortográfico (15), le siguen los gramaticales (4) y los morfosintácticos (2) (Ver Gráfico 5). Del total, sólo 5 fueron cometidos en fin de semana, lo que supone un $25 \%$ del total, no habiéndose producido ningún fallo en el bloque de deportes.

Gráfico 5. Tipología de los errores detectados en los rótulos de Antena 3

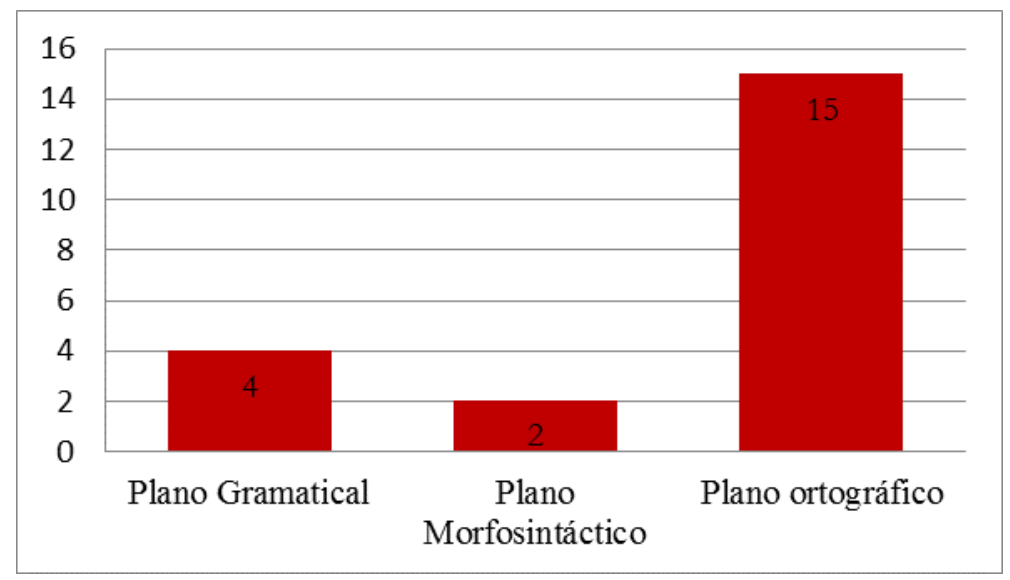

Fuente: Elaboración propia 
Los fallos morfosintácticos suelen corresponderse con la ausencia de artículos demostrativos. Como puede observarse en la Imagen 1, falta el artículo determinado masculino "el", de forma que debería poner "del Estado Islámico" en vez "de Estado Islámico". El 4 de julio también encontramos otro rótulo en el que se suprime el determinado femenino "la" delante de la palabra "víspera": "En víspera de la consulta" (Ver Imagen 2). La frase correcta sería "En la víspera de la consulta" o bien usando el plural "En vísperas de la consulta".

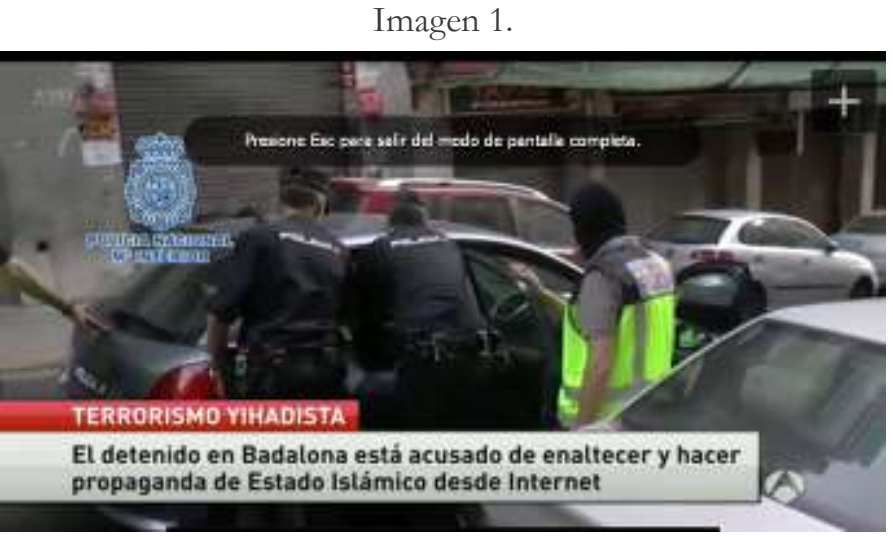

Fuente: Antena 3

Imagen 2.

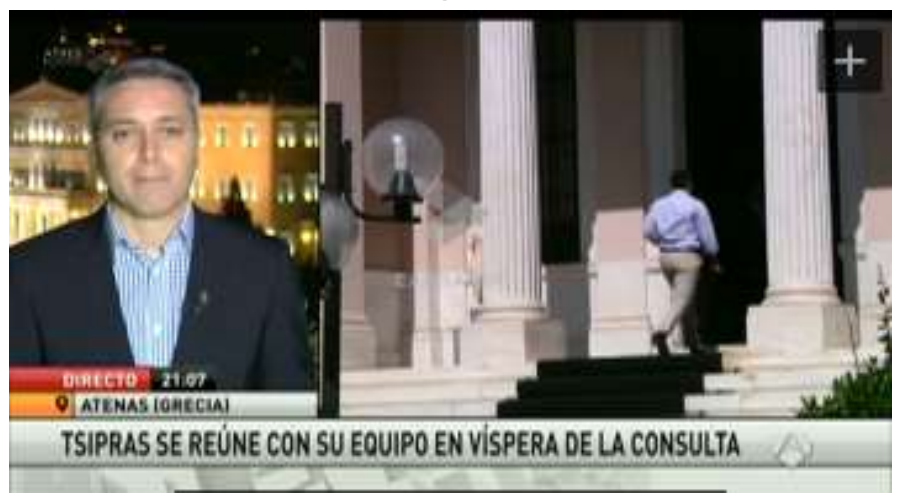

Fuente: Antena 3

En el Plano Gramatical hemos detectado 4 construcciones erróneas. Es el caso de "Comienzan hoy las emisiones de 'Mega"', del 1 de julio, que si siguiera el orden de Sujeto+Verbo+Predicado podría quedar de las dos maneras siguientes: "Las emisiones de 'Mega' comienzan hoy", o bien, "Hoy comienzan las emisiones de 'Mega"' (Ver Imagen 3). 
Imagen 3.

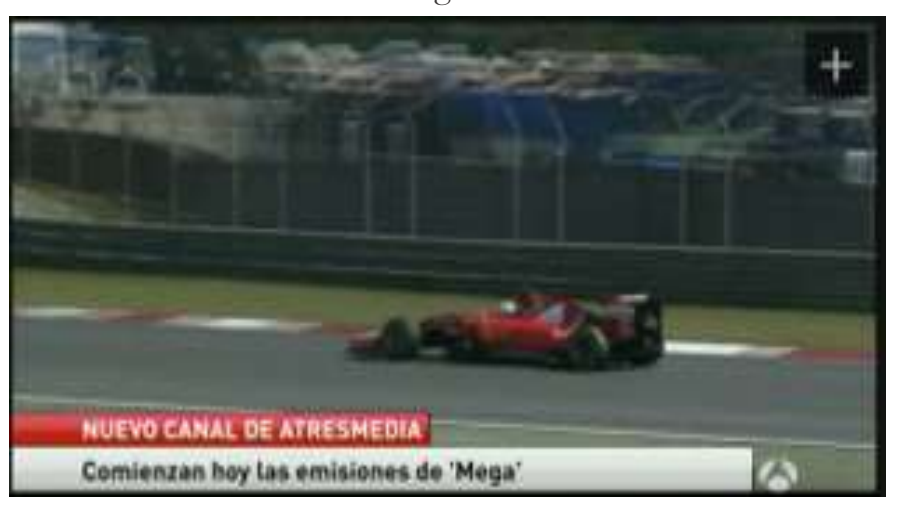

Fuente: Antena 3

A nivel ortográfico registramos en la misma proporción ausencia de tildes, erratas y faltas de ortografía. El 1 de julio detectamos que falta el acento en "situacion", a pesar de que se trata de una palabra aguda y a que la acentuación gráfica de las letras mayúsculas no es opcional, sino obligatoria, y afecta a cualquier tipo de texto (Ver Imagen 4). Un fallo similar lo encontramos en la falta de acento del adverbio de modo agudo y que termina en -n "también" (7 de julio). El caso contrario también se observa, la acentuación inadecuada de "Grecia" en "Grecía podría salir del euro" (8 de julio) (Ver Imagen 5).

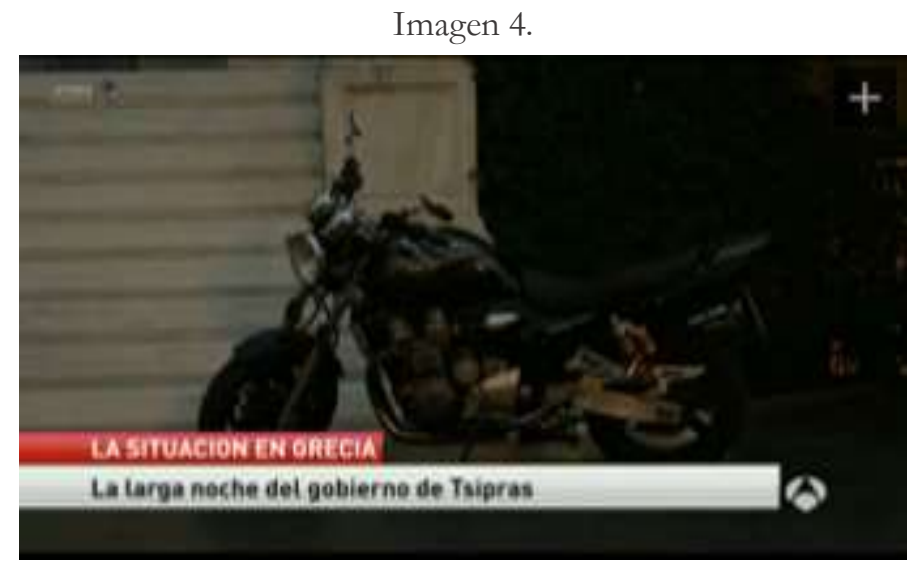

Fuente: Antena 3 


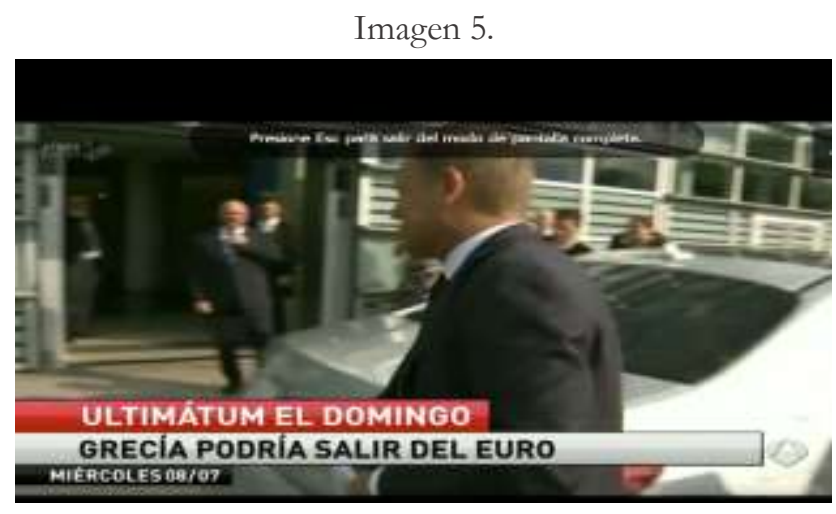

Fuente: Antena 3

En el apartado de erratas registramos la ausencia de la letra -c en la palabra "críticas", del 4 de julio, al tiempo que un desliz en el tabulador espaciador nos dejaba el siguiente rótulo el 7 de julio: "Nadie espera una cuerdo inmediato" (Ver Imagen 6).

Imagen 6.

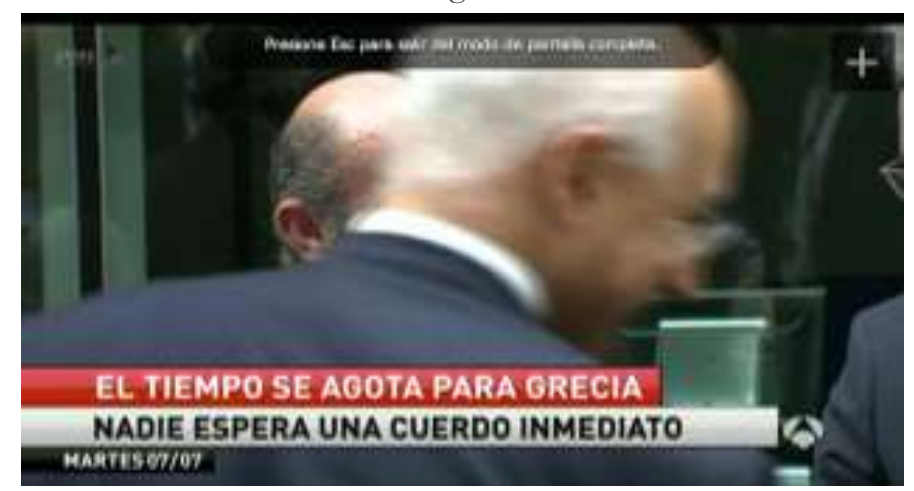

Fuente: Antena 3

En cuanto a las faltas de ortografía, el día 5 de julio encontramos que al hacer referencia a Antonio Samaras, se rotula "Ex- primer ministro", añadiendo un guión de forma indebida a una palabra prefijada de base pluriverbal (Ver Imagen 7).

Asimismo, se registra una ausencia de mayúsculas en el área de Finanzas cuando se hace referencia al "ministro griego de finanzas" y al hablar de las fiestas de San Fermín, conocidas como Sanfermines, y no como publica la cadena del grupo Atresmedia el 12 de julio "la imagen se produjo durante el 'chupinazo' de los sanfermines". El caso contrario lo encontramos el 6 de julio en el bloque de deportes cuando se rotula "La Gestora le hace el juego a Bertomeu", usando una mayúscula en "Gestora" cuando debería ir en minúscula. 
Imagen 7.

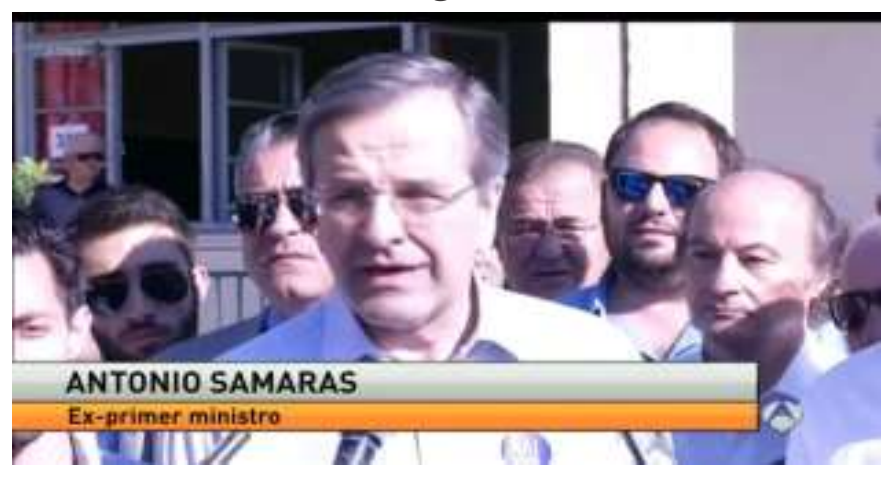

Fuente: Antena 3

Por último, detectamos un mal uso de los signos de puntuación, especialmente ausencia de comas o una inadecuada ubicación de las mismas. Estas erratas se dan sobre todo en el bloque de deportes donde encontramos ejemplos como el de la Imagen 8 en el que las comas son sustituidas por puntos. Así pues, la forma correcta del rótulo "Messi es el mejor del mundo. Pero mi ídolo es Iniesta. Me ha mandado un mensaje de bienvenida" sería "Messi es el mejor del mundo, pero mi ídolo es Iniesta, que me ha mandado un mensaje de bienvenida".

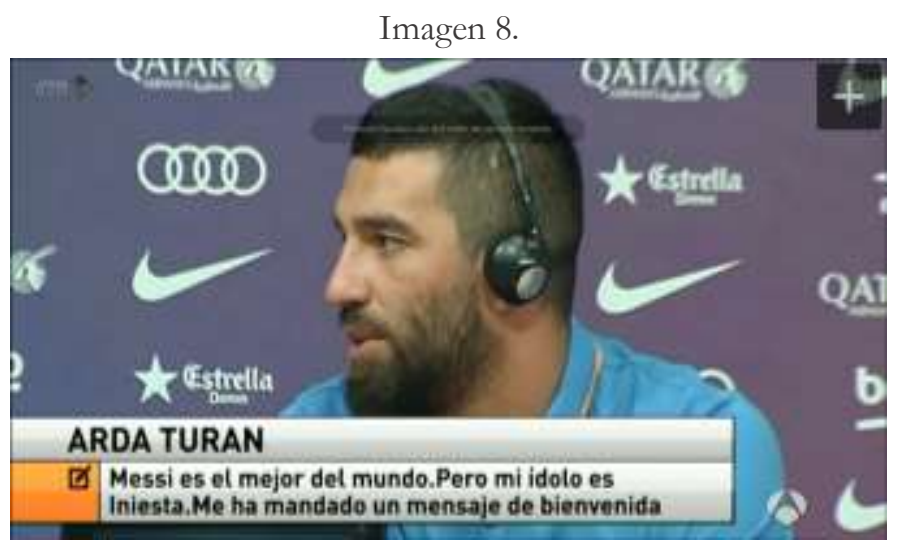

Fuente: Antena 3

En esta misma línea, el 14 de julio detectamos "Casillas fue una buena compra. No hay duda y es $100 \%$ bienvenido" en vez de "Casillas fue una buena compra, no hay duda, y es $100 \%$ bienvenido".

\subsection{Telecinco}

En caso de Telecinco hemos registrado un total de 81 rótulos con errores, de los cuales sólo 3 pertenecen al bloque destinado a deportes. 20 de esos errores fueron cometidos en fin de semana (28,9\% del total), todos ellos en el bloque de información general. La mayoría de erratas son relativas al Plano Ortográfico (43), le siguen las gramaticales (23) y las morfosintácticas (15) (Ver Gráfico 6). 
Gráfico 6. Tipología de los errores detectados en los rótulos de Telecinco

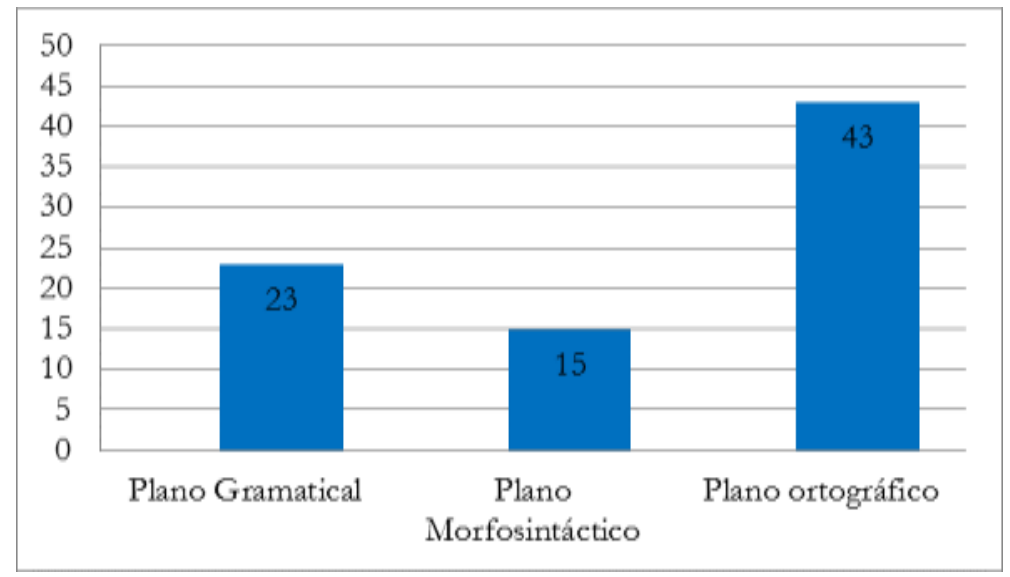

Fuente: Elaboración propia

A nivel morfosintáctico los errores más comunes son los relativos a faltas de concordancia entre género y número. Así, el 6 de julio encontramos que sobra la -s de "suministros" en "El 'corralito' bancario genera problemas de suministros en comercios, empresas y particulares", pues cuando se hace referencia al acto y consecuencia de suministrar el término correcto es "suministro", en singular.

El 11 de julio en "Con la llegada del fin de semana aumenta el número de personas que se suman a las fiestas", debería aparecer "se suma", pues "el número de personas" es singular. Otra errata similar la encontramos el día 12 en "De corte independentista, han hecho un llamamiento para apoyar a Artur Mas en su desafío soberanista", cuando en realidad, debería ser "ha hecho", pues el sujeto es singular, "un nuevo partido" (Ver Imagen 9).

Imagen 9.

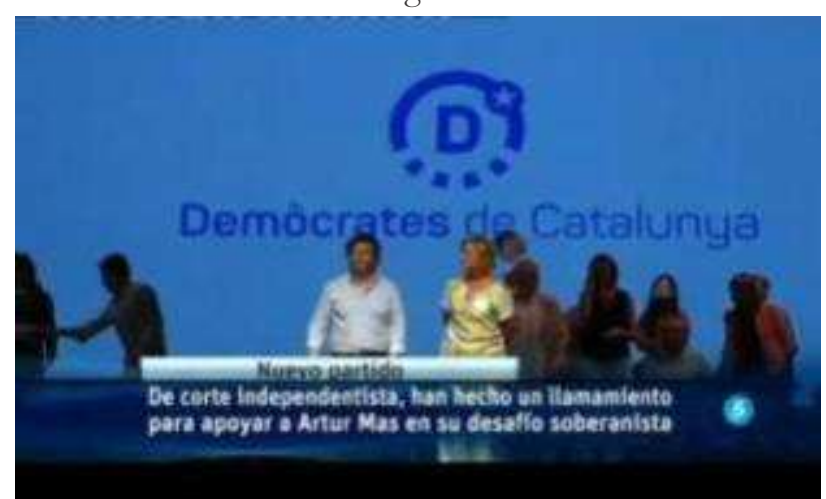

Fuente: Telecinco 
También observamos un exceso de artículos ("El PP busca las propuestas electorales con las que ilusionar de nuevo a sus votantes" donde sobra el determinado plural "las") y la contracción errónea "del Prat" en "La Audiencia decreta prisión para el presunto miembro del IS detenido en el aeropuerto del Prat", pues el nombre del aeródromo de Barcelona es El Prat.

En el plano gramatical detectamos 23 construcciones gramaticales fallidas, la mayoría debidas a una alteración del orden lógico de los elementos que conforman la frase. A modo de ejemplo reseñamos la encontrada el 1 de julio: "Una mujer de 84 años pasó 15 horas esperando en una rotonda a $40^{\circ}$ para coger un autobús”. La construcción idónea seguiría el principio de Sujeto+Verbo+Predicado, al tiempo que se prefiere el tiempo verbal en presente al pasado simple a fin de dar más sensación de actualidad, de manera que la frase quedaría: "Una mujer de 84 años pasa 15 horas esperando un autobús en una rotonda a $40^{\circ}$ ”.

También el 5 de julio rescatamos "Pase lo que pase en Grecia Rajoy afirma que España no sufrirá las consecuencias", cuando lo ideal sería "Rajoy afirma que España no sufrirá las consecuencias, pase lo que pase en Grecia" (Ver Imagen 10).

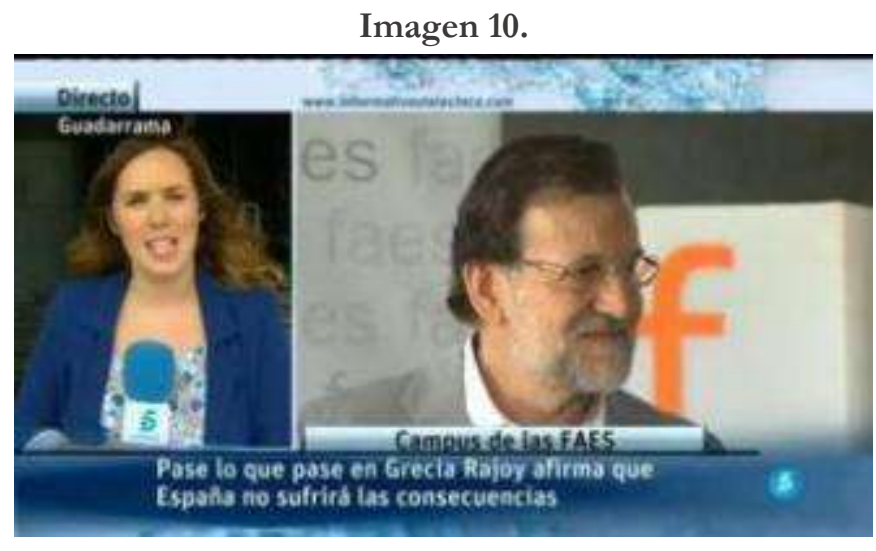

Fuente: Telecinco

Otros errores comunes son un exceso de preposiciones. El 7 de julio vemos que en el rótulo "La española se dedicaba a captar a niñas y a adolescentes para que viajaran a Siria", sobra la "a", quedando mucho mejor "captar niñas y adolescentes". Un caso similar lo encontramos en "Tsipras insiste en que con esta jornada electoral no se puede ignorar a la voluntad del pueblo", cuando la forma correcta es "ignorar algo", no "a algo".

De igual forma, en "Críticas al balance de 1688 personas fallecidas en el 2014, ocho más que en el año anterior", sobra el artículo "el" que va delante del año, debiendo quedar "Críticas al balance de 1688 personas fallecidas en 2014, ocho más que el año anterior” (Ver Imagen 11). 
Imagen 11.

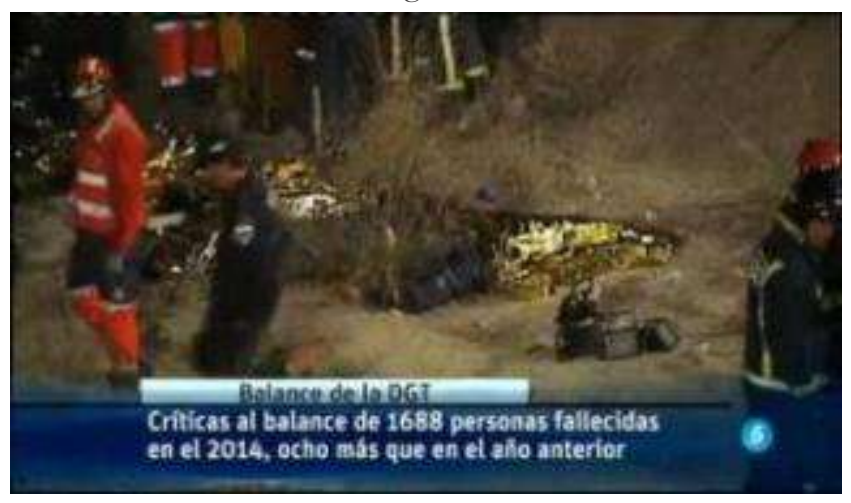

Fuente: Telecinco

Asimismo, el 4 de julio encontramos un claro caso de dequeísmo en "Rajoy advierte de que España podría parecerse a Grecia si el PP pierde el gobierno”. La formulación correcta sería “advierte que España” (Ver Imagen 12).

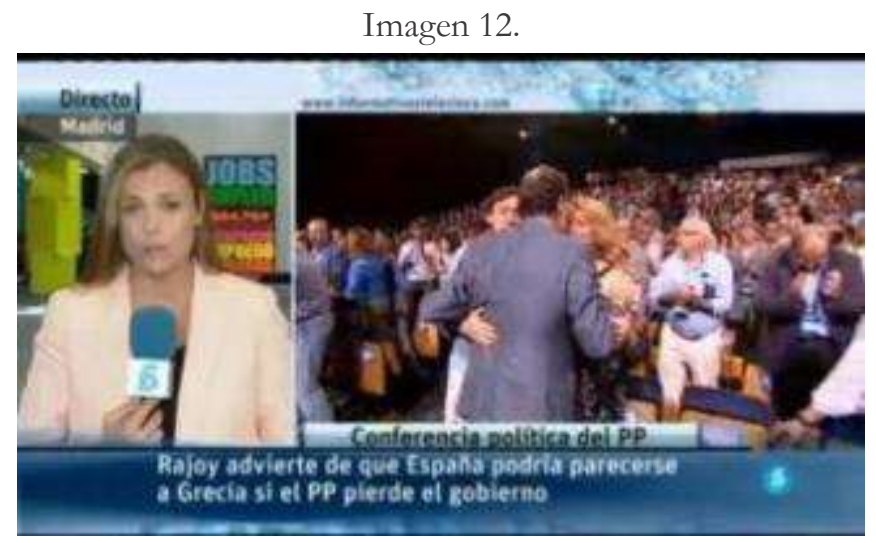

Fuente: Telecinco

En el plano ortográfico remarcamos 43 errores, siendo los más frecuentes los relativos a faltas de puntuación (12). Así, por ejemplo, en "Las temperaturas irán poco a poco subiendo hasta superar los 40 grados a partir del domingo", "poco a poco" debería ir entre comas; en "Desde hoy, los grandes camiones tendrán que viajar por autopista; se les bonificará el peaje”, el punto y coma se debería sustituir por "y" o "pero", y en "El detenido es un albanés que asegura que actuó, desesperado, porque había perdido 20.000 euros", es preciso eliminar la coma entre "actuó” y "desesperado".

También son numerosas las erratas (12). Algunas de ellas son "Erupción vocánica", donde falta la -1 de "volcánica"; "Diez provincias del centro peninsular en alerta naranja por riesgo importate de altas temperaturas", donde falta la -n de "importante" o "El trabajador del local que recibió los dispares evoluciona favorablemente dentro de la gravedad", donde debería poner "disparos". 
Respecto a las tildes comentar que hemos detectado 10 errores. Entre los más frecuentes están la no acentuación del sí cuando es adverbio: "Según los sondeos se produce un empate técnico entre los partidarios del si y del no" (5 de julio) y "Alemania apuesta por la victoria del si para retomar mañana las negociaciones" (6 de julio).

Otros acentos ausentes son "Sánchez" en "Susana Díaz sorprende con sus elogios a Pedro Sanchez ante los barones socialistas", o las esdrújulas "díscolo" y "límite" en "Tsipras negocia con los discolos de Syriza y otros partidos para aprobar las reformas cuanto antes" y "Limite al turismo", de los días 13 y 14 de julio (Ver Imagen 13).

Imagen 13.

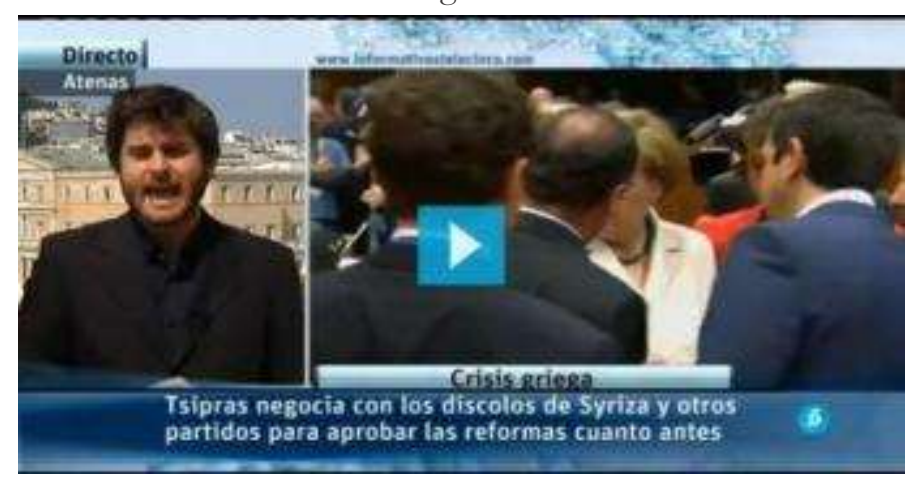

Fuente: Telecinco

De igual forma, hemos contabilizado hasta 9 faltas de ortografía. Entre ellas reseñamos "enpresarios" en vez de "empresarios", cuando sabemos que delante de -p siempre se escribe -m y "contrareloj" en vez de "contrarreloj" en "Negociación a contrareloj de los líderes europeos para alcanzar un acuerdo con el gobierno griego", del día 12 (Ver Imagen 14).

Imagen 14.

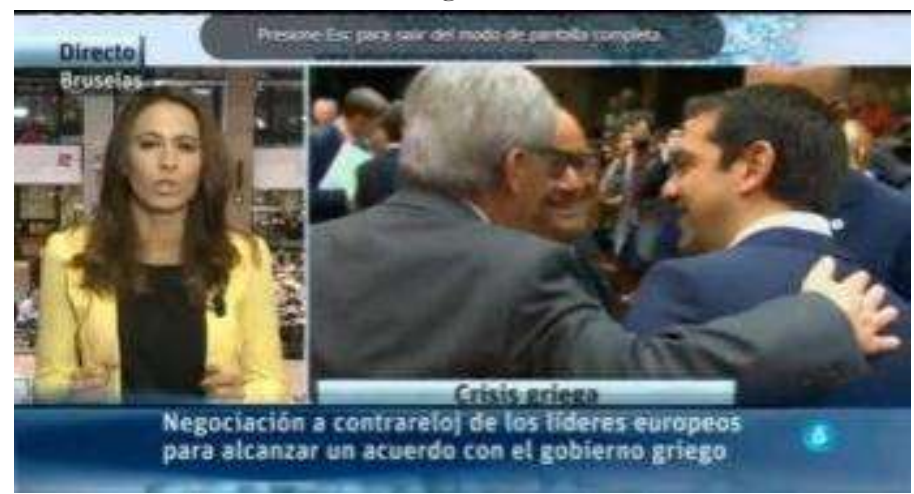

Fuente: Telecinco

También apreciamos la ausencia de mayúsculas en sustantivos comunes que designan organismos de carácter institucional como es el Parlamento (“Tsipras consigue el apoyo del parlamento para 
conseguir un tercer paquete de ayudas") y en los puntos cardinales: "Lo peor está hoy en el centro y sur peninsular con máximas por encima de los $40^{\circ}$ " y "Diez provincias del centro peninsular en alerta naranja por riesgo importate de altas temperaturas", donde también se observa la errata "importate" en vez de "importante".

Existen también faltas de atención como la reseñada a continuación donde no existe una temática entre el título y el texto: "Ola de calor" y "Obama presiona a Tsipras y a Merkel para que se encuentre una solución a la deuda griega", del 6 de julio (Ver Imagen 15).

\section{Imagen 15.}

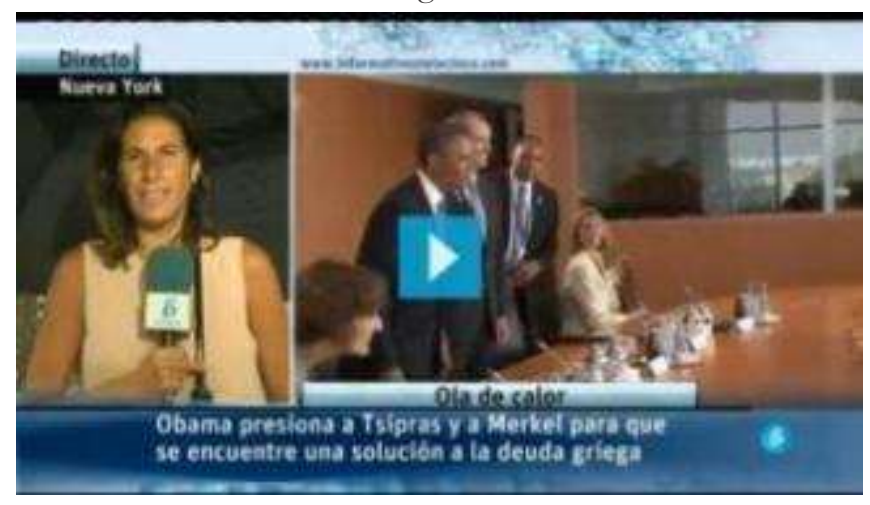

Fuente: Telecinco

\subsection{Televisión Española}

En el caso de TVE hemos registrado un total de 76 rótulos con errores, la mayoría de tipo ortográfico (46), frente a 20 gramaticales y 10 morfosintácticos (Ver Gráfico 7). El 25\% de los errores fueron cometidos en fin de semana (un total de 19), aunque ninguno en el bloque deportivo.

Gráfico 7. Tipología de los errores detectados en los rótulos de TVE

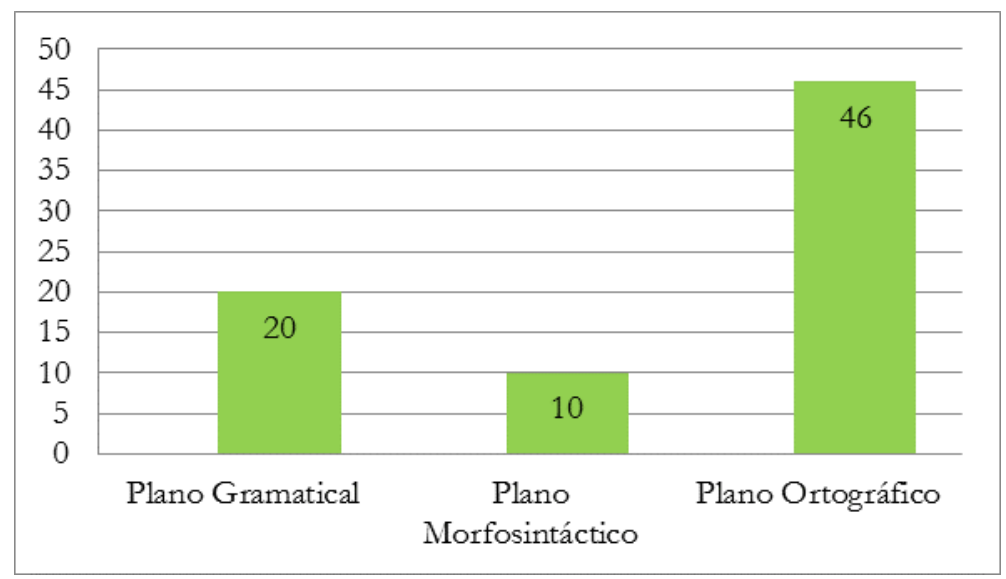

Fuente: Elaboración propia 
A nivel morfosintáctico los errores más frecuentes se corresponden con la ausencia de artículos demostrativos, tal y como apreciamos en "Su portal de la transparencia recibe 50.000 visitas en un año, lo más consultado los sueldos de altos cargos", donde debería indicar "de los altos cargos", o "Niega colocación dos bombas trampa" en vez de "Niega la colocación de dos bombas trampa", del 14 de julio (Ver Imagen 16).

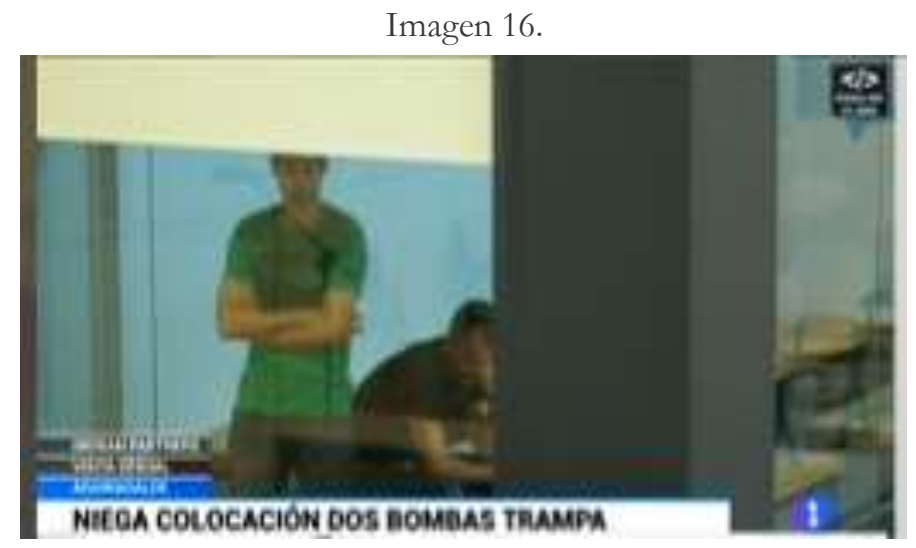

Fuente: TVE

También observamos el caso contrario, un exceso de artículos. Así el 4 de julio encontramos "Nairo Quintana, el primer favorito en cruzar la meta", cuando lo correcto sería "Nairo Quintana, primer favorito en cruzar la meta".

En otras ocasiones vemos una confusión de género, "las" por "los" en "David Cameron preside junto al alcalde de Londres una de las ceremonias en recuerdo de las 52 fallecidos", aunque también es frecuente el uso de demostrativos cuando lo idóneo sería un determinante posesivo, "su traspaso al Oporto", en "Real Madrid y Casillas cierran el acuerdo y en horas será oficial el traspaso al Oporto".

Dos decenas de errores a nivel gramatical son los detectados durante nuestro periodo de estudio en los rótulos de TVE. Fundamentalmente, se trata de una mala construcción gramatical que se aleja de la fórmula tradicional de Sujeto + Verbo+ Predicado y que conlleva una incorrecta interpretación de los mensajes aportados.

Un ejemplo bastante evidente lo hallamos en el rótulo del 10 de julio: "29 evacuados, más de 2.000 hectáreas quemadas y el fuego sigue sin control y nivel uno". En este caso la frase correcta debería ser "29 evacuados y más de 2.000 hectáreas quemadas. El fuego, de nivel uno, sigue sin control". Ese mismo día también encontramos "Fin de semana de nuevo de temperaturas extremas en el Centro y el Sur de la península", siendo la construcción más lógica "Nuevo fin de semana de temperaturas extremas en el Centro y el Sur de la península" 
Otros errores comunes son un exceso de preposiciones. Así, en "Los líderes europeos y los acreedores aguardan a los resultados de la consulta", la forma correcta sería "aguardar algo" no "a algo".

También se produce un mal uso de los tiempos verbales, tal es el caso de "Por proselitismo en Internet a favor del Estado Islámico este año ya han detenido a 46 personas”, del 4 de julio, cuando la frase correcta sería "Este año ya han sido detenidas 46 personas por proselitismo en Internet a favor del Estado Islámico" (Ver Imagen 17).

Imagen 17.

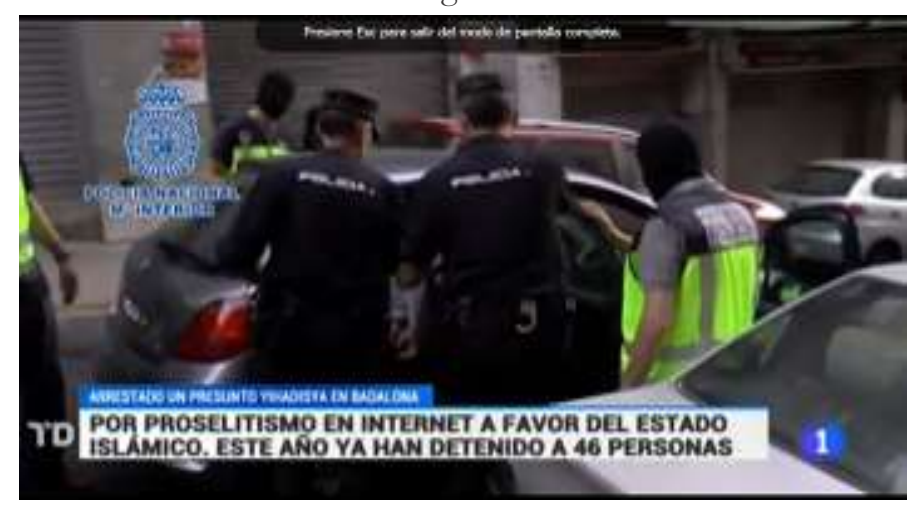

Fuente: TVE

Dentro del Plano Ortográfico, tal y como ocurría en las cadenas privadas, los errores de puntuación son los más frecuentes, especialmente la ausencia de comas y la mala colocación de los puntos. Ello puede apreciarse en "Segunda etapa y primera salida en línea rumbo a Francia Alberto Contador ha salido a 58" del maillot amarillo", donde falta un punto y seguido entre "Francia” y "Alberto" que establezca el fin de una oración y el comienzo de la siguiente.

Según la RAE, el uso de la coma es incompatible con la conjunción "y", sin embargo, TVE rotula el 6 de julio: "El piloto ileso, y 13 espectadores heridos" (Ver Imagen 18).

Imagen 18.

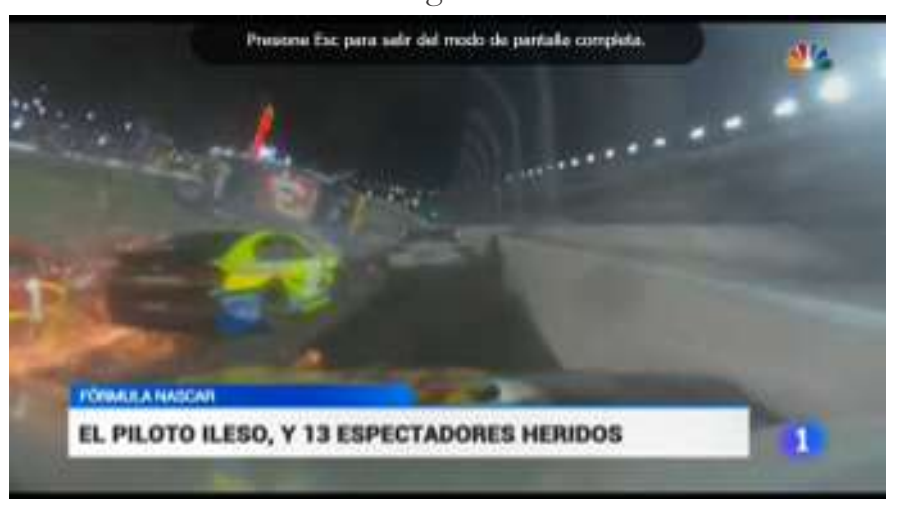

Fuente: TVE 
En otras ocasiones es la ausencia de comas lo que llama nuestra atención. Así, en "El incendio cercano al Parque Natural de Cazorla tiene un perímetro de 1.800 hectareas", la construcción correcta sería "El incendio, cercano al Parque Natural de Cazorla, tiene un perímetro de 1.800 hectáreas". En este caso, además, encontramos una falta de acentuación de la esdrújula "hectáreas".

En cuanto a la acentuación detectamos hasta 9 erratas, entre ellas "iba" acentuado en "Detenido un menor por la muerte de una limpiadora que le sorprendió cuando supuestamente íba a robar", o "huído", cuando la RAE (2011) establece que "el diptongo -ui no se tilda en los participios de los verbos terminados en -uir, como es el caso de huir", en "La policia busca a dos hombres que han huído tras retener a 18 trabajadores". Aquí, además, detectamos la ausencia de tilde en "policía", una palabra grave terminada en dos vocales, siendo una de ellas débil (i), y cargando sobre ella la pronunciación (Ver Imagen 19).

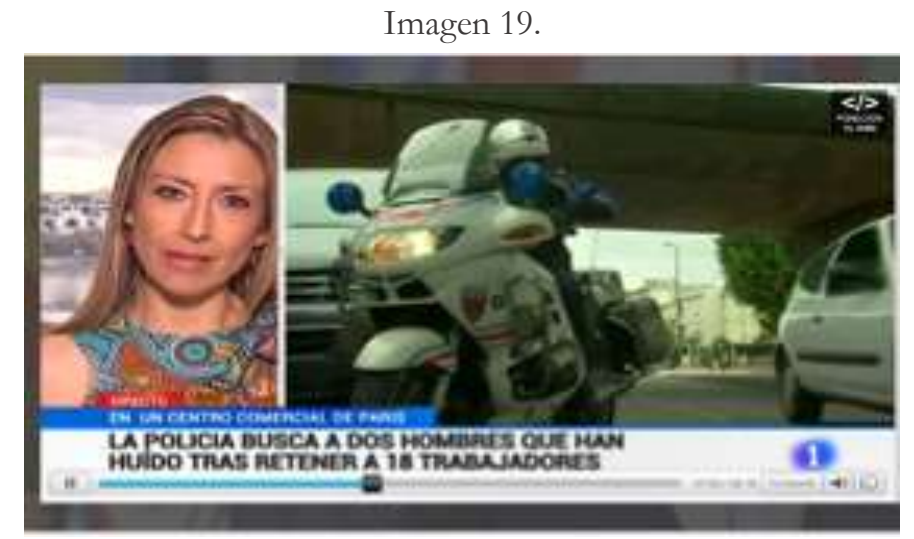

Fuente: TVE

Hasta un total de 11 erratas involuntarias se han colado entre los rótulos de TVE, entre ellas, la ausencia de texto informativo. Así, el 2 de julio leíamos "Centros territoriales" o "Brasil gana a Brasil en la final femenina”, tal y como puede apreciarse en la Imagen 20.

Imagen 20.

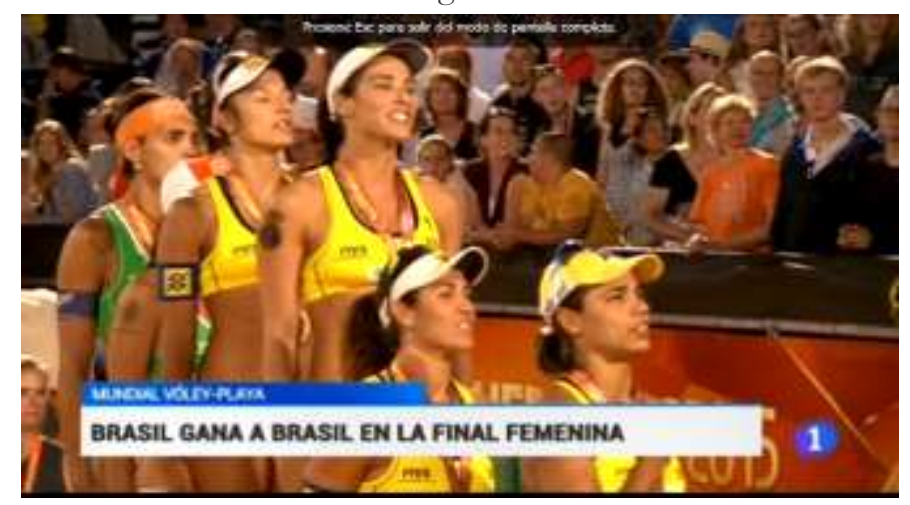

Fuente: TVE 
Por último, en el apartado de faltas de ortografía apreciamos dos usos incorrectos de la palabra "ex pareja", cuando el término correcto sería "expareja", pues a partir de la edición de la Ortografía de 2010 "ex-" debe someterse a las normas generales que rigen la escritura de todos los prefijos y, por tanto, escribirse unido a la base a la que afecta cuando esta es univerbal, es decir, constituida por una sola palabra.

De igual forma, hemos detectado una falta de unanimidad a la hora de utilizar las comillas, así pues, el 11 de julio la fiesta de los Bous a la Mar aparecía entrecomillada y al día siguiente no, como puede apreciarse en las siguientes imágenes (Ver Imagen 21).

Imagen 21.
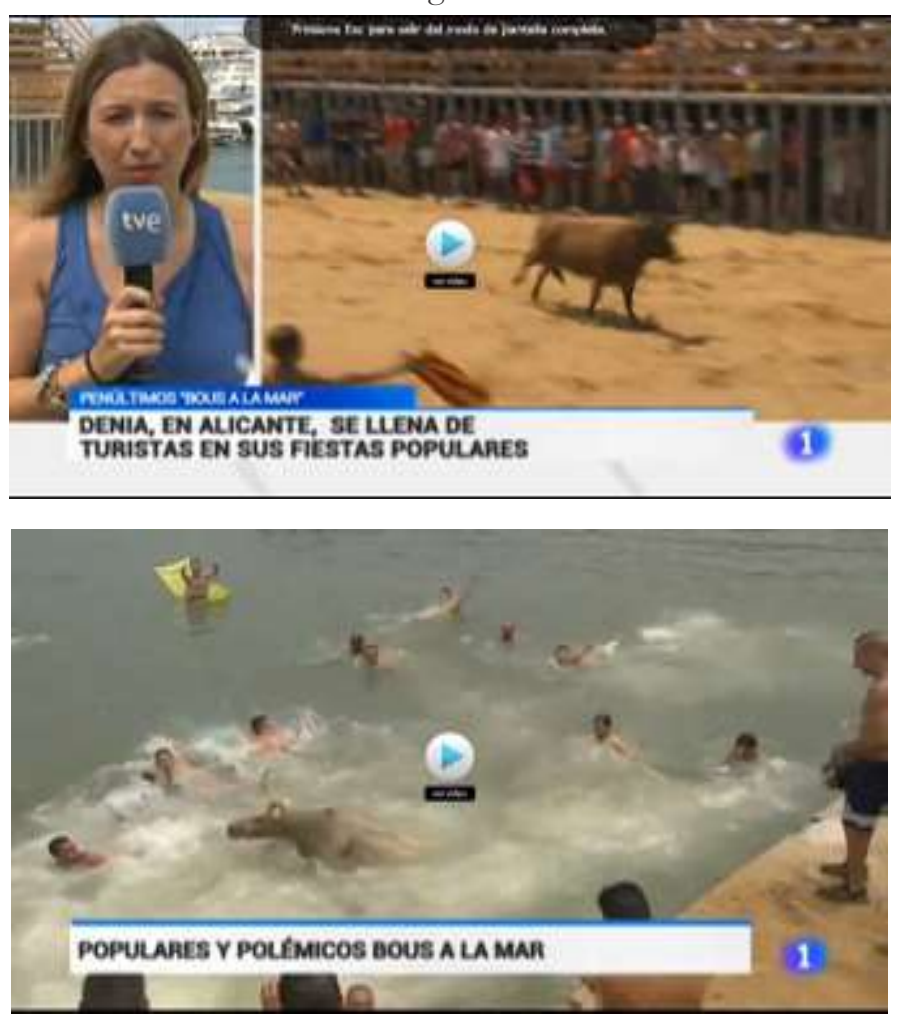

Fuente: TVE

\section{Discusión y Conclusiones}

En base al análisis realizado hemos comprobado que Televisión Española es la cadena que más rótulos utiliza en sus informativos así como la que más errores comete. No obstante, en términos porcentuales es Telecinco, con casi un 17\%, la emisora que más incorrecciones presenta en sus textos frente al escaso 4\% registrado en Antena 3.

La mayoría de las erratas son de índole ortográfico, fundamentalmente faltas de puntuación, lo que evidencia que las personas encargadas de redactar estos rótulos desconocen las normas básicas que rigen el uso de puntos y comas. Le siguen a corta distancia las erratas involuntarias y 
las tildes, siendo las menos abundantes las faltas de ortografía que, curiosamente, son las que más se registran en Antena 3.

A nivel morfosintáctico, Telecinco y Televisión Española son las cadenas que menor cuidado prestan a la concordancia entre género y número, al tiempo que son frecuentes las ausencias o mala utilización de los artículos demostrativos. Esta tónica también la observamos en el Plano Gramatical, ya que ambas emisoras son las que peor articulan sus oraciones y ello conduce a numerosos errores de interpretación.

Los datos obtenidos en este estudio vienen a corroborar nuestra hipótesis de partida, que existe una actitud laxa respecto al cuidado de la ortografía en los rótulos de televisión, un aspecto que se da por igual en cadenas privadas y públicas, pero que es especialmente reprobable en el caso de Televisión Española, pues atenta contra la responsabilidad que tiene la emisora pública de garantizar una información rigurosa y de calidad y que ella misma reivindica en su Libro de Estilo.

En este sentido, ya apuntaba Martínez Albertos (2005) que:

Los medios de comunicación de titularidad pública (agencias de prensa, periódicos, radios, canales de televisión, etc.) tienen como objetivo prioritario de su función social la preocupación por la corrección lingüística de los mensajes que difundan por cada uno de sus canales de difusión. De esta manera, estos medios colaborarán eficazmente para mantener y reforzar la unidad lingüística sustancial del idioma español en todos los países y regiones del mundo en que actualmente es hablado.

Estudiados los informativos como dos subconjuntos, la información de actualidad y el bloque deportes, podemos afirmar que los errores se cometen con mayor asiduidad en el apartado informativo. Esto es especialmente evidente en el caso de las cadenas privadas cuyo porcentaje de rótulos erróneos en el apartado deportivo es de tan sólo un 5\% frente al 17\% registrado por TVE. También en los deportes las faltas de índole ortográfico son las más abundantes, especialmente, las correspondientes a ausencia de tildes y faltas de puntuación.

Asimismo, son más frecuentes los errores durante los fines de semana, hasta el punto de suponer el 25\% de las erratas totales encontradas, porcentaje que llega casi al 29\% en el caso de Telecinco. Eso sí, no hemos registrado ningún rótulo erróneo en el bloque deportivo del fin de semana.

Los errores ortográficos son los más abundantes en Antena 3 y TVE, mientras que a nivel morfosintáctico y gramatical destaca Telecinco, la cadena de Mediaset es la que peor articula sus oraciones observándose una mayor incidencia en la ausencia de correspondencia entre género y número durante los fines de semana. 
De todo lo anteriormente expuesto llegamos a la conclusión de que pese a su misión de entretener, instruir e informar atendiendo a un lenguaje correcto y asequible para la ciudadanía, los informativos de televisión registran un elevado número de incorrecciones lingüísticas.

Los errores analizados pueden deberse a la inmediatez imperante en el formato noticioso audiovisual, así como a la limitación de espacio que imponen los rótulos sobreimpresos, esta restricción de caracteres favorece la existencia de construcciones sintácticas poco ortodoxas que dificultan la comprensión de titulares y textos, así como la ausencia de artículos. Otro elemento condicionante puede ser que el deseo de emplear una lengua moderna y cercana al pueblo conlleve faltas de ortografía, de concordancia y redundancias.

No obstante, la mayoría de las incorrecciones encontradas no tienen justificación, ya que, por lo general, proceden de un desconocimiento de la norma lingüística o son debidas a la escasa dedicación empleada por los rotulistas a su estudio y desarrollo.

Dado que los medios de comunicación tienen un profundo compromiso cultural con la sociedad y puesto que los informativos se identifican con la parte de imagen que la empresa quiere dar de sí misma, al tiempo que la audiencia los considera una fuente de información fiable, debemos ser inflexibles ante los fallos encontrados y desde el punto de vista del lingüista pedirles tres cosas: que no olviden la importancia de la unidad de la lengua dentro de la comunidad hispanohablante, que revisen los textos de los rótulos antes de insertarlos y que consulten sus dudas con las gramáticas y diccionarios que recogen las normas lingüísticas a seguir.

\section{Bibliografía}

ANDUEZA, B. Y PÉREZ, R. (2014). Los rótulos de los informativos de televisión: un nuevo lenguaje audiovisual. En Sierra, J. y García, F. (Coor.). Tecnología y narrativa audiovisual. Madrid: Fragua.

ATRESMEDIA CORPORACIÓN (2012). “Código Deontológico Servicios Informativos Antena 3 Televisión”. Recuperado de http://www.atresmediacorporacion.com/a3document/2012/01/10/DOCUMENTS/00002 100002.pdf

BARRIO, I., GONZÁLEZ, J., PADÍN, L., PERAL, P., SÁNCHEZ, I. Y TARÍN, E. (2012). Modelos de Investigación Educativa. Madrid: Universidad Autónoma.

BERELSON, B. (1952). Content Analysis in Communications Research. Nueva York: Free Press.

BOBO, M. (2005). La función social de los medios y la situación actual de la televisión en España. Comunicar, 25, 2-12. 
BULDÚ, J. (2011): “La estructura de las Redes Sociales". Recuperado de: http://www.madrimasd.org/blogs/redes-complejas

CEBRIÁN, M. (2003). Información televisiva: mediaciones, contenidos, expresión y programación. Madrid: Síntesis.

CREMADES, J. (2007). Micropoder: La fuerza del ciudadano en la era digital. Madrid: EspasaCalpe.

CRESWELL, J.W. y Plano Clark, V. (2011). Designing and Conducting Mixed Methods Research. Thousand Oaks: Sage Publications.

CRIGLER, A., JUST, M. Y NEUMAN, R. (1994). Interpreting visual versus audio messages in television news. Journal of Communication, 44, 132-149.

DE PABLOS, J. M. (1997). La lengua española en la formación del periodista. I congreso Internacional de Lengua Española. Recuperado de http://congresosdelalengua.es/zacatecas/ponencias/prensa/comunicaciones/depablos2.ht $\underline{\mathrm{m}}$

DIAZ-BONE, R. (2007). Gibt es eine qualitative Netzwerkanalyse. Forum Qualitative Sozialforschung, 8(1), 311-343.

FACEBOOK (2016): "Faltas de ortografía en medios de comunicación". Recuperado de https://www.facebook.com/Faltas-de-ortograf\%C $3 \%$ ADa-en-medios-decomunicaci $\%$ C3\%B3n-228459780535756/info/?tab=page_info

GÓMEZ, A. (2005). Los libros de estilo de los medios de comunicación: necesidad de un acuerdo. En Guerrero, S. y Medina, A. Lengua Española y medios de comunicación: norma y uso. Madrid: VG Ediciones.

GUERRERO, C. (1999). Contenido y audiencia de los informativos: Canal Sur TV y TVE en Andalucía. Una aproximación metodológica. Revista Latina de Comunicación Social, 15.

HERVÁS, C. (2002). El diseño gráfico en televisión: Técnica, lenguaje y arte. Madrid: Ediciones Cátedra.

HUERTAS, A. Y PERONA, J.J. (1999). Redacción y locución en medios audiovisuales. Barcelona: Bosch. 
MORALES, F. (2001). Diseño de un modelo de construcción informativa audiovisual eficiente: una propuesta para la generación de efectos de sentido. Compós, 14 (1), 1-19.

MORENO, P. (2003). El periodismo informativo en televisión: lenguaje, género y estilo. Estudios sobre el Mensaje Periodístico, 9, 269-280.

MARTÍNEZ ALBERTOS, J. L. (2005). La responsabilidad de los comunicadores en el lenguaje de los medios: la corrección académica. Revista Latina de Comunicación Social, 60.

PASTOR, J.M. (2014). Análisis cuantitativo en los informativos de televisión: un modelo para la categorización del 'Gaur Egun’ de ETB Televisión Vasca. Estudios sobre el Mensaje Periodístico, Vol. 20, 2, 805-819.

PERICOT, J. (2002). Mostrarpara decir. Barcelona: Servicio de publicaciones de la UAB.

PESTANO, J. (2008). Tendencias actuales en la estructura y contenidos de los informativos de televisión. Revista Latina de Comunicación Social, 63, 453- 462.

KANTARMEDIA (2015). Boletin de audiencia. Recuperado de http://www.kantarmedia1.es/archivos/index

KRIPPENDORF, K. (1990). Metodología de análisis de contenido. Teoría y práctica. Barcelona: Paidós.

RAE (2010). Diccionario panhispánico de dudas. Madrid: Espasa.

- (2011) Ortografía de la lengua española. Madrid: Espasa.

ROIZ, M (1994). Técnicas modernas de persuasión. Madrid: Eudema

RTVE (2015): Manual de estilo. Recuperado de http://manualdeestilo.rtve.es/tve/2-2-algunasdeficiencias-en-la-elaboracion-de-noticias/

ROMERO, V. (2005). Titulares; usos y norma. En Guerrero, S. y Medina, A. Lengua Española y medios de comunicación: norma y uso (pp.125-137). Madrid: VG Ediciones. 
SECO, M. (2003). El laberinto de las palabras: introducción a los diccionarios (I). Revista de la Fundación Juan March, 326, 30-35.

THOMAS, G. (2011). A typology for the case study in social science following a review of definition, discourse and structure. Qualitative Inquiry 17(6), 511-521. DOI:10.1177/1077800411409884

VALERO, J. L. (2009). Clasificación del grafismo de contenido en los informativos de televisión. Trípodos, 25, 179-196. 


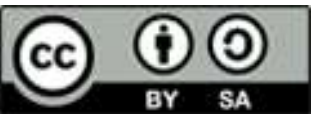

Licencia Creative Commons

Miguel Hernández Communication Journal

mhcj.es

\section{Forma de citar este artículo en las bibliografías}

Marián Alonso González (2016): “La ortografía en televisión. Estudio de los informativos de Antena 3, Telecinco y TVE”, en Miguel Hernández Communication Journal, nº7, páginas 287 a 323. Universidad Miguel Hernández, UMH (Elche-Alicante). Recuperado el__ de de $20 \_$_e: link del artículo en mhjournal.org] 